\title{
Hypersonic Aerothermoelastic Studies for Reusable Launch Vehicles
}

\author{
J.J. McNamara*, B.J. Thuruthimattam*, P.P. Friedmann ${ }^{\dagger}$, and K.G. Powell ${ }^{\ddagger}$ \\ Department of Aerospace Engineering \\ University of Michigan \\ 3001 François-Xavier Bagnoud Bldg., 1320 Beal Ave \\ Ann Arbor, MI 48109-2140 \\ Ph: (734) 763-2354 Fax: (734) 763-0578 \\ email: peretzf@umich.edu \\ R. Bartels ${ }^{\S}$ \\ Aeroelasticity Branch \\ NASA Langley Research Center \\ Hampton, VA 23681
}

\begin{abstract}
An aeroelastic and aerothermoelastic analysis of a three-dimensional low aspect ratio wing, representative of a fin on hypersonic vehicles, is carried out using piston theory, and Euler aerodynamics. Studies on grid convergence are used to determine the appropriate computational domain and resolution for this wing in hypersonic flow, using both Euler and Navier-Stokes aerodynamics. Hypersonic computational aeroelastic responses are then generated, using Euler aerodynamics in order to obtain frequency and damping characteristics for comparison with those from first and third order piston theory solutions. Results indicate that the aeroelastic behavior is comparable when using Euler and third order piston theory aerodynamics. The transonic aeroelastic behavior of the wing is also analyzed using Euler aerodynamics. The aerothermoelastic behavior of the wing, using piston theory aerodynamics, is studied by incorporating material property degradation and thermal stresses due to non-uniform temperature distributions. Results indicate that aerodynamic heating can substantially reduce aeroelastic stability. Finally, hypersonic aeroelastic behavior of a generic vehicle resembling a reusable launch vehicle is performed using piston theory. The results presented serve as a partial validation of the CFL3D code for the hypersonic flight regime.
\end{abstract}

\section{Nomenclature}

\footnotetext{
a Nondimensional offset between the elastic axis and the midchord, positive for elastic axis behind midchord

$a_{\infty} \quad$ Speed of sound

$b \quad$ Semi-chord

$c \quad$ Reference length, chord length of double-wedge airfoil

$C_{L}, C_{M}, C_{D} \quad$ Coefficients of lift, moment about the elastic axis, and drag

$C_{p} \quad$ Coefficient of pressure

$f_{1}() \quad$ Function relating Mach number and temperature

$h \quad$ Airfoil vertical displacement at Elastic Axis

$I_{\alpha} \quad$ Mass moment of inertia about the Elastic Axis

$K_{\alpha}, K_{h} \quad$ Spring constants in pitch and plunge respectively; $K_{\alpha}=I_{\alpha} \omega_{\alpha}^{2}, K_{h}=m \omega_{h}^{2}$

$M \quad$ free stream Mach number

*Ph.D. Candidate, Student Member

${ }^{\dagger}$ François-Xavier Bagnoud Professor of Aerospace Engineering, Fellow AIAA

¥Arthur F. Thurnau Professor of Aerospace Engineering, Associate Fellow AIAA

$\S$ Senior Research Engineer, Senior Member AIAA
} 


\begin{tabular}{|c|c|}
\hline $\mathbf{M}, \mathbf{K}$ & Generalized mass and stiffness matrices of the structure \\
\hline$m$ & Mass per unit span \\
\hline$M_{f}$ & Flutter Mach number \\
\hline$n_{m}$ & Number of modes used \\
\hline$p$ & Pressure \\
\hline$p_{\infty}$ & Free-stream pressure \\
\hline Q & Generalized force vector for the structure \\
\hline$Q_{i}$ & Generalized force corresponding to mode $i$ \\
\hline$q_{\infty}$ & Dynamic pressure \\
\hline$q_{i}$ & Modal amplitude of mode $i$ \\
\hline$r_{\alpha}$ & Nondimensional radius of gyration \\
\hline$S$ & Surface area of the structure \\
\hline$S_{\alpha}$ & Static mass moment of wing section about elastic axis \\
\hline$T_{R E F}$ & Reference temperature used to scale nondimensional temperature distribution \\
\hline$T_{E}$ & Kinetic energy of the structure \\
\hline$t$ & Time \\
\hline$t_{h}$ & Airfoil half thickness \\
\hline$U_{E}$ & Potential energy of the structure \\
\hline$V$ & Free stream velocity \\
\hline$v_{n}$ & Normal velocity of airfoil surfaces \\
\hline$w$ & Displacement of the surface of the structure \\
\hline$x_{\alpha}$ & $\begin{array}{l}\text { Nondimensional offset between the elastic axis and the cross-sectional center of gravity, } \\
\text { positive for center of gravity behind elastic axis }\end{array}$ \\
\hline$x, y, z$ & Spatial Coordinates \\
\hline$Z(x, y, t)$ & Position of structural surface \\
\hline$\alpha$ & Airfoil pitch displacement about the Elastic Axis \\
\hline$\alpha_{s}$ & Static angle of attack \\
\hline$\gamma$ & Ratio of specific heats \\
\hline$\mu_{m}$ & Mass ratio \\
\hline$\rho$ & Air density \\
\hline$\omega_{\alpha}, \omega_{h}$ & Natural frequencies of uncoupled pitch and plunge motions \\
\hline$\Phi$ & Modal matrix \\
\hline$\phi_{i}$ & mode shape for mode $i$ \\
\hline$\tau$ & Thickness ratio; $\tau=\frac{t_{h}}{h}$ \\
\hline & Damping ratio $\quad b$ \\
\hline$\dot{(}), \ddot{(}$ & First and second derivatives with respect to time \\
\hline
\end{tabular}

\section{Introduction and Problem Statement}

Hypersonic aeroelasticity and aerothermoelasticity was a vibrant and active area of research in the late 1950's and during the 1960's as evident from Refs. ${ }^{1-4}$ This research has been instrumental in providing the basis for the aerothermoelastic design of the space shuttle. For a considerable time period there was only limited interest in this area until the advent of the National AeroSpace Plane (NASP).

In recent years, renewed activity in hypersonic flight research has been stimulated by the need for a low cost, single-stage-to-orbit (SSTO) or two-stage-to-orbit (TSTO) reusable launch vehicle (RLV) and the long term design goal of incorporating air breathing propulsion devices in this class of vehicles. The $\mathrm{X}$ 33 , an example of the former vehicle type, was a $1 / 2$ scale, fully functional technology demonstrator for the full scale VentureStar. Another ongoing hypersonic vehicle research program is the NASA Hyper-X experimental vehicle effort. Other activities are focused on the design of unmanned hypersonic vehicles that meet the needs of the US Air Force. The present study is aimed at enhancing the fundamental understanding of the aeroelastic behavior of vehicles that belong to this category and operate in a typical hypersonic flight envelope.

Vehicles in this category are based on a lifting body design. However, stringent minimum-weight requirements imply a degree of fuselage flexibility. Aerodynamic surfaces, needed for control, are also flexible. Furthermore, to meet the requirement of a flight profile that spans the Mach number range from 0 to 15, the vehicle must withstand severe aerodynamic heating. These factors combine to produce unusual aeroelastic problems that have received only limited attention in the past. Furthermore, it is important to emphasize that testing of aeroelastically scaled wind tunnel models, a conventional practice in subsonic and supersonic flow, is not feasible in the hypersonic regime. Thus, the role of aeroelastic simulations is more important for this flight regime than in any other flight regime.

Previous studies in this area can be separated into several groups. The first group consists of studies focusing on panel flutter, which is a localized aeroelastic problem representing a small portion of the skin on 
the surface of the hypersonic vehicle. Hypersonic panel flutter has been studied by a number of researchers, focusing on important effects such as aerodynamic heating, ${ }^{5}$ composite construction ${ }^{6,7}$ and nonlinear structural models with initial panel curvature. ${ }^{8,9}$ A comprehensive review of this research can be found in a recent survey paper. ${ }^{10}$

The second group of studies in this area was motivated by a previous hypersonic vehicle, namely the NASP. ${ }^{11-17}$ However, some of these studies dealt with the transonic regime, because it was perceived to be quite important. Spain et al. ${ }^{12}$ carried out a flutter analysis of all-movable NASP-like wings with slab and double-wedge airfoils. They found that using effective shapes for the airfoils obtained by adding the boundary layer displacement thickness to the airfoil thickness improved the overall agreement with experiments. Aerothermoelastic analyses of NASP-like vehicles found that aerodynamic heating altered the aeroelastic stability of the vehicle through the degradation of material properties and introduction of thermal stresses. ${ }^{15-17}$

The third group of studies is restricted to recent papers that deal with the newer hypersonic configurations such as the X-33 or the X-34. Reference 18 considered the X-34 launch vehicle in free flight at $M=8.0$. The aeroelastic instability of a generic hypersonic vehicle, resembling the X-33, was considered in Ref. 19 . It was found that at high hypersonic speeds and high altitudes, the hypersonic vehicle is stable, when piston theory is used to represent the aerodynamic loads. Sensitivity of the flutter boundaries to vehicle flexibility and trim state were also considered. ${ }^{19}$ In another reference, ${ }^{20}$ CFD-based flutter analysis was used for the aeroelastic analysis of the X-43 configuration, using system identification based order reduction of the aerodynamic degrees of freedom. Both the structure and the fluid were discretized using the finite element approach. It was shown that piston theory and ARMA Euler calculations predicted somewhat similar results.

From the studies on previous hypersonic vehicles, ${ }^{11,20-22}$ one can identify operating envelopes for each vehicle. A graphical representation of these operating conditions is shown in Fig. 1. This figure is a convenient illustration of the operational envelope of generic hypersonic vehicles.

Recently, the authors of this paper described an aeroelastic analysis capability for generic hypersonic vehicles in the Mach number range $0.5<M<15.0$, using computational aeroelasticity. ${ }^{23,24}$ The computational tool consisted of a combination of the CFL3D code and a finite element model of a generic hypersonic vehicle utilizing MSC.NASTRAN. The focus of these studies ${ }^{23,24}$ was on the aeroelastic behavior of a two dimensional double-wedge airfoil, operating in the Mach number range of $2.0<M<15.0$ at various altitudes. In these studies, the double-wedge airfoil was identified as a suitable candidate for exploring the various computational aspects of hypersonic aeroelasticity. This paper continues to explore fundamental aspects of hypersonic aeroelasticity using computational tools and it focuses on three-dimensional low aspect ratio wings and complete generic hypersonic vehicle configurations. The specific objectives of the paper are:

1. Generate aeroelastic stability boundaries of a typical cross-section, based on the double-wedge airfoil and a three-dimensional low aspect ratio wing, in hypersonic flow using piston theory, for comparison with more refined computations.

2. Study the time-step and mesh requirements for the reliable computation of the unsteady airloads for this particular problem using the Euler and Navier-Stokes options of CFL3D.

3. Compare the aeroelastic behavior initially predicted using piston theory aerodynamics with refined solutions for the same problem, using unsteady aerodynamic loads based on complete Euler and NavierStokes solutions.

4. Incorporate aerodynamic heating in an approximate manner in order to calculate aerothermoelastic responses.

5. Extend the analysis to a generic hypersonic vehicle that has features resembling a reusable launch vehicle.

Finally, it is important to note that these objectives not only enhance our fundamental understanding of hypersonic aeroelasticity, but also make a valuable contribution towards the validation of the CFL3D code for hypersonic flight conditions.

\section{Method of Solution}

The computational aeroelastic solutions in the present study are obtained using the CFL3D code. ${ }^{25}$ The CFL3D code is used to generate both steady and unsteady air loads, and it also produces the aeroelastic transients and response solutions. The combination between the fluid and structure is accomplished using the free vibration modes of the vehicle. 


\section{A. Euler/Navier-Stokes Solver in CFL3D}

The aeroelastic analysis of the system is carried out using the CFL3D code. The code uses an implicit, finite-volume algorithm based on upwind-biased spatial differencing to solve the time-dependent Euler and Reynolds-averaged Navier-Stokes equations. Multigrid and mesh-sequencing are available for convergence acceleration. The algorithm, which is based on a cell-centered scheme, uses upwind-differencing based on either flux-vector splitting or flux-difference splitting, and can sharply capture shock waves. For applications utilizing the thin-layer Navier-Stokes equations, different turbulence models are available. For time-accurate problems using a deforming mesh, an additional term accounting for the change in cell-volume is included in the time-discretization of the governing equations. Since CFL3D is an implicit code using approximate factorization, linearization and factorization errors are introduced at every time-step. Hence, intermediate calculations referred to as "subiterations" are used to reduce these errors. Increasing these subiterations improves the accuracy of the simulation, albeit at increased computational cost.

\section{B. Aeroelastic Option in CFL3D}

The aeroelastic approach underlying the CFL3D code is similar to that described in Refs. 26 and 27. The equations are derived by assuming that the general motion $w(x, y, t)$ of the structure is described by a number of modes represented by Eqn. (1):

$$
w(x, y, t)=\sum_{i=1}^{n_{m}} q_{i}(t) \phi_{i}(x, y)
$$

The functions $\phi_{i}(x, y)$ represent the free vibration modes of the vehicle obtained from a finite element model. The aeroelastic equations of motion are obtained from Lagrange's equations,

$$
\frac{d}{d t}\left(\frac{\partial T_{E}}{\partial \dot{q}_{i}}\right)-\frac{\partial T_{E}}{\partial q_{i}}+\frac{\partial U_{E}}{\partial q_{i}}=Q_{i}, \quad i=1,2, \ldots
$$

which yield

$$
\mathbf{M} \ddot{q}+\mathbf{K} q=\mathbf{Q}(\mathbf{q}, \dot{\mathbf{q}}, \ddot{\mathbf{q}}), \quad \mathbf{q}^{T}=\left[q_{1} q_{2} \ldots\right]
$$

where the elements of the generalized force vector are given by,

$$
Q_{i}=\frac{\rho V^{2}}{2} c^{2} \int_{S} \phi_{i} \frac{\Delta p d S}{\rho V^{2} / 2 c^{2}}
$$

The aeroelastic equations are written in terms of a linear state-space equation (using a state vector of the

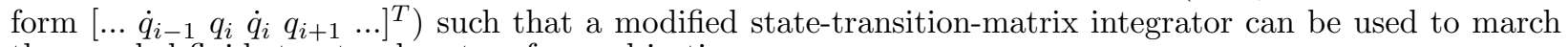
the coupled fluid-structural system forward in time.

The aeroelastic capabilities of CFL3D, based on this modal response approach for obtaining the flutter boundary, have been partially validated for the transonic regime for the first AGARD standard aeroelastic configuration for dynamic response, Wing 445.6. The results of flutter calculations using Euler aerodynamics are given in Ref. 28 and those using Navier-Stokes aerodynamics are given in Ref. 29. However, these calculations were limited to the transonic regime.

\section{Computational Methods for Fluid-Structure Coupling}

Prediction of the dynamic response of a flexible structure in a fluid requires the simultaneous solutions of the equations of motion of the structure and the fluid. In order to impose the kinematic boundary conditions on the fluid mesh at the new time step, the location and velocity of the fluid-structure boundary must first be known. This requires the solution of the entire system of equations for the structure, a task which cannot be carried out till the current surface pressure is known, which depends on the solution of the fluid domain and thus also on the unknown boundary conditions during the current time step. In addition, the discretized model of the structure uses a Lagrangian approach by following a point located on the structure over time, while the discretized model of the fluid uses an Eulerian approach by computing the flow quantities at a specific location in space over time. Therefore, coupling the two systems is a fairly complicated endeavor. A straightforward approach to the solution of the coupled fluid-structure system requires changing the fluid grid at each time-step, which is computationally very expensive. Therefore, several different approaches have emerged as alternatives to partial regridding in transient aeroelastic computations, among them being dynamic meshes, ${ }^{30}$ the space-time formulation, ${ }^{31-33}$ the Arbitrary/Mixed Eulerian-Lagrangian formulation, ${ }^{34,35}$ the multiple-field formulation ${ }^{36,37}$ and the transpiration method. ${ }^{20,38}$

In the dynamic mesh approach, ${ }^{30}$ the edges of each element are represented as springs, with stiffnesses inversely proportional to the length of the edge. Grid points on the outer boundary of the mesh are held fixed, and the instantaneous locations of points on the inner boundary (body) are prescribed by the body motion. At each time-step, the static equilibrium equations along the coordinate axes are solved iteratively at each 
interior node of the grid for its displacements. This is accompanied by a predictor-corrector method, which first predicts the displacements according to a linear extrapolation and then corrects these displacements using several Jacobi iterations of the static equilibrium equations. To avoid errors induced by the moving mesh, a geometric conservation law needs to be satisfied which relates the change in the area/volume of a cell to the area/volume swept by the boundary of the cell. This is the method used in CFL3D.

The Space-Time approach ${ }^{31-33}$ attempts to discretize the space-time domain using finite elements, i.e., the finite element mesh covers the complete space-time domain. The variational formulation of the problem is written over the associated space-time domain. While the motion of the boundary is explicitly unknown, the location of the boundary nodes at the end of a time-step are related to the other unknowns (i.e. velocity, displacement) at the boundary of the spatial domain. The solution to this space-time variational problem includes the complete motion of the spatial domain within the time-period of interest. Another advantage of this approach is that it allows the use of spatially local time steps within a temporally accurate formulation. ${ }^{31}$ When applying this method to aeroelastic problems, a simultaneous solution of the fluid and the structure over the combined space-time domains is the natural extension. However, in such a case, the solution and variational function spaces needs to include functions which are discontinuous across the interface.

The Lagrangian approach applied to fluid flows provides a clear delineation of interfaces and well-resolved details of the flow, but is limited by its inability to cope with large motions of particles as seen in high speed flows. On the contrary, in the Eulerian formulation, large motions can be handled with relative ease, but generally at the expense of precise feature definition and resolution of detail. Both the Lagrangian and Eulerian approaches present advantages and drawbacks, and the Arbitrary Lagrangian-Eulerian (ALE) method attempts to combine the best features of both descriptions. ${ }^{34}$ This is done by considering a reference frame which moves at a non-zero velocity, and is also different from the particle velocity. The conservation laws are then rederived in this frame. However, this method is primarily intended to simplify the treatment of the boundary nodes, or to provide a rezoning capability for the fluid mesh. In the Mixed LagrangianEulerian method, ${ }^{35}$ the governing equations for both the fluid and the structure are formulated in integral conservation form based on the same Lagrangian-Eulerian description. At the fluid-structure boundary, there is a switch from the Lagrangian-Eulerian description to a Lagrangian description, and from Cartesian to generalized coordinates. The entire fluid-structure continuum is treated as one continuum dynamics problem, while allowing for different discretizations in the two domains. The same numerical integration algorithm can then be used throughout all elements in the field meshes covering the fluid-structure system.

In the Multiple Field formulation, ${ }^{36}$ the moving mesh is viewed as a psuedostructural system with its own dynamics and thus the coupled transient aeroelastic problem is formulated as a three-field problem: the fluid, the structure and the dynamic mesh. The four-field formulation of aerothermoelasticity ${ }^{37}$ was proposed as an extension of the three-field formulation above, to study phenomena involving fluid-structure-thermal interaction. At present, only a one-way thermal mechanical coupling has been implemented. Thus, a change in temperature only causes stress and deformations, but not vice versa. The transfer of thermal quantities from the structure to the flow at the interface utilizes a wall law function, and the transfer of discretized heat fluxes from the fluid to the structure is expressed via a heat flux equilibrium condition.

Finally, the transpiration method is a means by which to "trick" the flow solver into seeing a deflection in the mesh that is not actually there. If a change in the surface normal is known, from a structural dynamic solver for example, then this change in the normal surface can be applied directly to the existing CFD grid through a slight modification of the existing surface normals. With transpiration, the nodes affected by a surface deflection simply require a modification of the existing surface normals. Even though the surface is not actually deflected, the flow solver sees the deflected normal at the corresponding nodal locations. However, this method has seen limited usage in computational aeroelasticity.

\section{General Overview of the Solution Process}

The solution process of the computational aeroelasticity problem used in the present study is shown in Fig. 2. First, the vehicle geometry is created using CAD software, and from this geometry a mesh generator, in this case ICEM CFD, is used to create a multi-block structured mesh for the flow domain around the body. In parallel, an unstructured mesh is created for the finite element model of the structure using the same nodes on the vehicle surface that were used to generate the fluid mesh. Subsequently, the fluid mesh is used to compute the flow around the rigid body using a CFD solver, which consists of the CFL3D code developed by NASA Langley Research Center. The structural mesh is used to obtain the free vibration modes of the structure by finite element analysis using MSC.NASTRAN. The modal displacements at the nodes in the fluid mesh is then obtained by interpolation from the nodes in the structural mesh. Using the flow solution as an initial condition, and the modal information, an aeroelastic steady state is obtained. For a geometry with vertical symmetry at zero angle of attack the aeroelastic steady state is the same as the undeflected state. Next, the structure is perturbed in one or more of its modes by an initial modal velocity condition, and the transient response of the structure is obtained. To determine the flutter conditions at a given altitude, aeroelastic transients are computed at several Mach numbers and the corresponding dynamic pressures. The frequency and damping characteristics of the transient response for a given flight condition and vehicle configuration can be determined from the moving block approach, which analyzes the Fourier transform of a discretely sampled transient signal. ${ }^{39}$ This approach applied to the same altitude and vehicle configura- 
tion for a range of Mach numbers results in a series of damping values for the system. The flutter Mach number can be estimated from this series by interpolating the damping data points to identify zero damping.

\section{E. Computational Model for the Three-Dimensional Low Aspect Ratio Wing and Grid Con- vergence Studies}

Few studies ${ }^{40,41}$ have been carried out that validate CFL3D for the hypersonic regime. In part, this is because CFL3D was not originally designed for modeling hypersonic flow, and does not contain support for computing real-gas effects. However, depending on the flows to be studied, and on which flow variables are the most relevant, sufficiently accurate solutions may be calculated even when ignoring real gas effects. These studies ${ }^{40,41}$ compared the pressure distributions and static and dynamic stability derivatives of cones and ogive-cylinder bodies obtained using CFL3D with results obtained using a unified hypersonic/supersonic panel method in the range $3<M<6$. However, no attempt was made in these studies to compare aeroelastic stability boundaries obtained with CFL3D.

A systematic validation of the CFL3D code for flutter analysis in the hypersonic regime has never been undertaken. To validate aeroelastic stability boundaries computed with CFL3D, it is important to identify and use simple configurations for which aeroelastic stability boundaries can be computed using alternative approaches. Previously, the authors of this paper studied extensively the aeroelastic behavior of a simple two-dimensional, double-wedge airfoil using the Euler and Navier-Stokes solvers in CFL3D, as well as higher order piston theory, in the hypersonic regime. ${ }^{23,24}$ The three-dimensional low aspect ratio wing, shown in Fig. 3, which is representative of a fin or control surface on a generic hypersonic vehicle, is a logical choice for extending the previous results to the three-dimensional case. Generating results for this configuration using Euler and Navier-Stokes unsteady aerodynamic loads, and comparing them with results obtained using an independently developed aeroelastic code based on piston theory, represents another validation of CFL3D in the hypersonic regime.

In CFD computations, insufficient fluid mesh "quality" is detrimental to accurate prediction of the flow characteristics and aerodynamic loads present on a body. The development of a high quality mesh, however, becomes a challenging task for three-dimensional configurations due to limits in computational resources. While the mesh must have sufficient resolution to adequately capture the flow characteristics, the number of cells in the mesh is limited by the available computational resources. Due to this restriction, it is necessary to distribute the cells around the body in an efficient manner.

The fidelity of a mesh is determined by studying the steady flow around a particular body. The steady flow around the low aspect ratio wing is an excellent test case due to its double-wedge cross-section. At supersonic Mach numbers and small angles of attack, an attached oblique shock will form at the leading and trailing edges of the wing, while an expansion fan is present at mid-chord. For inviscid flow, the surface pressure is a step function, where the discontinuity appears at mid-chord.

In order to determine the best distribution of cells around the wing, four different meshes were constructed with different computational domains and cell spacing. The root section plane of the computational domain for each test case (MESH1, MESH2, MESH3 and MESH4) is shown in Figs. 4 - 7. MESH2 - MESH4 have the same computational domain, however the cell spacing normal to the wing surface is varied as shown. The computational domains of MESH1 and MESH4 are shown in Figs. 8 and 9, respectively. Note that MESH1 occupies a larger domain around the wing than MESH2-MESH4. Also, the cell spacing in MESH1 is primarily uniform, however, a small decrease in cell spacing is present at the leading and trailing edges and mid-chord. As illustrated in Figs. 5 - 7, the outer boundary of MESH2-MESH4 surrounding the leading surface of the wing (leading edge to mid-chord) was set at a distance $10 \%$ beyond the shock that forms at $M=5.0$. This Mach number was chosen as an upper bound of the computational domain for the leading portion of the wing since it was not expected that flutter calculations would have to be carried out below $M=5.0$. The number of cells used in each test case is listed in Table 1.

The inviscid pressure distribution for each test case, at a cross-section located at $75 \%$ span of the wing, is shown in Fig. 10. The computations were conducted at both a moderate $(M=5.0)$ and high $(M=16.0)$ Mach number, at an altitude of 40,000 ft. The importance of the mesh used in the flow calculations is clearly illustrated. As stated, the pressure at a cross-section of the wing should be a step function, with the pressure constant from leading edge to mid-chord, and mid-chord to trailing edge; with the discontinuity at midchord. However, as illustrated in Fig. 10, the surface pressure predicted using MESH1 is non-uniform over the forward and aft sections. This indicates that neither the shock nor the expansion fan is captured well, and the discontinuity in pressure is distributed over a large number of streamwise grid points. Furthermore, while MESH2 - MESH4 all capture the leading edge shock, only MESH4 correctly simulates a sharp change in pressure at mid-chord. This is particularly visible at $M=16.0$. Comparison of Figs. 11 and 12 illustrates the efficiency of the smaller computational domain at high Mach number. Most of the fluid cells in MESH4 are within the domain of influence of the flow, while the majority of the cells in MESH1 are outside the domain of influence. Based on these observations, MESH4 was selected from amongst the four grids since it accurately and efficiently captured the characteristics of the flow around the wing.

A necessary step in the selection of a mesh for fluid computations is the determination of a converged flow solution for a static case. Therefore, a convergence study of MESH4 was conducted in order to determine the necessary resolution for accurate prediction of the wing airloads. To perform this study, four additional 
grids ( 2 coarser, 2 finer) based on MESH4, were constructed. The $C_{L}$ and $C_{M}$ at $\alpha_{s}=1^{\circ}$ were compared by calculating the percent difference between the results obtained for each mesh to the finest mesh $\left(5.1 \times 10^{6}\right.$ cells). These quantities are listed in Tables 2 and 3. In general, most of the coarser grids are within $2 \%$ of the finest grid predictions, while only the coarsest grid at the highest Mach number has a difference greater than $3 \%$. In addition, the $L_{2}$ and $L_{\infty}$ norms of the error in $\frac{p}{p_{\infty}}$ at each grid point on the surface of the wing were calculated for each mesh relative to the finest mesh. These quantities are listed in Tables 4 and 5 . Typically, in a mesh-convergence study, the goal is to see the error norms decrease as the grid gets finer, to an order of magnitude of fractions of a percent. However, that goal is really only achievable in smooth solutions. The flows computed here are discontinuous, and so these discrete error norms are dominated by the fact that the shock location and thickness, when slightly different on the current mesh and finest mesh, leads to $\mathcal{O}(1)$ error norm. In contrast, the lift and moment are less sensitive to exact locations of the discontinuities since they are integral functions of the pressure. Therefore, the $C_{L}$ and $C_{M}$ calculations are selected in this case as the best indicators of convergence. Comparing $C_{M}$ obtained with the various grids is also significant due to the important role of the torsional moment in aeroelastic stability studies. Steady flow solutions, using MESH4 with $0.63 \times 10^{6}$ cells, and the Euler solver in CFL3D, are obtained in 1 hour using 6 Athlon 2000MP CPUs.

The boundary layers in hypersonic flow are much thicker than those present at more moderate Mach numbers. ${ }^{42,43}$ In addition, the shock and expansion fan lie close to the body. This implies that the boundary layer occupies a large portion of the shock layer. ${ }^{42,43}$ Based on these observations, MESH4 could also be used for Navier-Stokes computations, since the majority of grid points are clustered in the vicinity of the wing surface. As a further test of this fluid mesh, the grid convergence study described previously was repeated using the Navier-Stokes solver in CFL3D. Tables $6-8$ list the percent difference in $C_{L}, C_{M}$, and $C_{D}$ respectively for each mesh relative to the finest mesh $\left(5.1 \times 10^{6}\right.$ cells $)$. These results imply that more resolution is necessary in the mesh when solving the Navier-Stokes equations as opposed to the Euler equations; however, these results are preliminary.

Tables 9 and 10 list the $L_{2}$ and $L_{\infty}$ norms, respectively, for each grid. Similar to the inviscid case, the $L_{2}$ and $L_{\infty}$ norms of the surface pressure are large due to large changes in pressure at the leading edge and mid-chord of the wing. Therefore, as before, comparisons of the airloads are a better indicator of convergence.

Figure 13 illustrates the flow pattern around at the $75 \%$ span station of the wing using MESH4 with $0.63 \times 10^{6}$ cells. Steady flow solutions, using MESH4 with $0.63 \times 10^{6}$ cells, and the Navier-Stokes solver in CFL3D, are obtained in 1.4 hours using 6 Athlon 2000MP CPUs.

Based on these results, MESH4 was selected for the aeroelastic computations on the low aspect ratio wing. With $0.63 \times 10^{6}$ cells, this grid is a $57 \times 353 \times 33$ C-grid with 353 points around the wing and its wake (289 points on the wing surface), 57 points extending spanwise from the root (49 points on the wing on the wing surface), and 33 points extending radially outward from the surface. Figure 9 illustrates the computational domain for this mesh. The root section plane, shown in Fig. 7, of the computational domain extends one-half root chord-lengths downstream. The boundary of the grid surrounding the wing, from the leading edge to mid-chord, extends to a distance $10 \%$ beyond the shock that forms at $M=5.0$. The computational domain in the spanwise direction also extends beyond the tip of the wing by $35 \%$ of the semi-span length. Furthermore, the grid is tapered, in all three dimensions, so as to be compatible with the geometric taper of the wing.

\section{F. Piston Theory Aerodynamics}

Piston theory is a simple inviscid unsteady aerodynamic theory, that has been used extensively in supersonic and hypersonic aeroelasticity. It provides a point-function relationship between the local pressure on the surface of the vehicle and the component of fluid velocity normal to the moving surface. ${ }^{44,45}$ The derivation utilizes the isentropic "simple wave" expression for the pressure on the surface of a moving piston,

$$
\frac{p(x, t)}{p_{\infty}}=\left(1+\frac{\gamma-1}{2} \frac{v_{n}}{a_{\infty}}\right)^{\frac{2 \gamma}{(\gamma-1)}}
$$

where

$$
v_{n}=\frac{\partial Z(x, y, t)}{\partial t}+V \frac{\partial Z(x, y, t)}{\partial x}
$$

The expression for piston theory is based on a binomial expansion of Eq. (5), where the order of the expansion is determined by the ratio of $\frac{v_{n}}{a_{\infty}}$. Reference 45 suggested a third-order expansion, since it produced the smallest error of the various orders of expansion used when compared to the limiting values of pressure, namely the "simple wave" and "shock expansion" solutions. The third-order expansion of Eq. (5) yields

$$
p(x, t)-p_{\infty}=p_{\infty}\left[\gamma \frac{v_{n}}{a_{\infty}}+\frac{\gamma(\gamma+1)}{4}\left(\frac{v_{n}}{a_{\infty}}\right)^{2}+\frac{\gamma(\gamma+1)}{12}\left(\frac{v_{n}}{a_{\infty}}\right)^{3}\right]
$$


Combining Eqns. 1, 4, 6, and 7 yields the generalized forces obtained from piston theory. First order piston theory is obtained when only the first term in Eqn. 7 is used, while third order piston theory is obtained when all three terms in Eqn. 7 are used.

\section{Results and Discussion}

Comparison of aeroelastic stability results based on Euler, Navier-Stokes and piston theory in Refs. 23 and 24 provided an indication about the importance of viscosity, and the effectiveness of piston theory in approximating the aeroelastic behavior of a double-wedge airfoil. A similar approach is pursued here for a three-dimensional low aspect ratio wing that resembles the wing of the Lockheed F-104 Starfighter. This configuration is used to compare first and third order piston theory with Euler aerodynamics. Furthermore, the aerothermoelastic behavior of this configuration is studied in an approximate manner by introducing thermal stresses and material property degradation due to temperature effects. Finally, the aeroelastic behavior of a generic hypersonic vehicle is studied using first and third order piston theory.

In Ref. 24, a careful numerical study was carried out to determine the appropriate time step sizes required for modeling the unsteady aerodynamics when using the Euler and Navier-Stokes solvers in CFL3D. These results were based on a double-wedge airfoil resembling a typical cross-section of the low aspect ratio wing located at $75 \%$ of span, which is shown in Fig. 14. The parameters describing this configuration are listed in Table 11, and further details are given in Ref. 24. The aeroelastic behavior of the double-wedge airfoil, obtained using different unsteady aerodynamic loads, is shown in Fig. 15. Use of piston theory yields flutter at $M_{f}=12.01$, while the Euler loads reduce the boundary to $M_{f}=9.39$, and the Navier-Stokes based loads result in a further reduction to $M_{f}=8.97$.

\section{A. Aeroelastic Behavior of a Three-Dimensional Low Aspect Ratio Wing}

The parameters describing the physical properties of the three-dimensional low aspect ratio wing are shown in Table 12 and Fig. 3. This wing is assumed to be representative of the control surface of a generic hypersonic vehicle and therefore its aeroelastic behavior at hypersonic speeds is studied. The natural frequencies and modes, shown in Fig. 16, were determined by comparing them with the bending and torsional frequencies and total mass of a wing that resembles the Lockheed F-104 wing. Flutter of the low aspect ratio wing was calculated using first and third order piston theory aerodynamics and Euler aerodynamics in the hypersonic regime. Furthermore, the aeroelastic behavior of the low aspect ratio wing was also studied through the transonic regime using Euler aerodynamics. The time step size used was selected to accommodate 50 steps per cycle of the highest frequency mode, for the Euler simulations. For the low aspect ratio wing, this resulted in a smaller time step than that required for modeling the unsteady aerodynamic loads.

The sensitivity of the aeroelastic behavior of the wing to the number of modes is illustrated in Table 13. It is evident that increasing the number of modes from 5 to 8 has little effect on the aeroelastic behavior when piston theory aerodynamics is used. However, it is also clear that at least five modes are needed to capture the aeroelastic behavior. Analysis of the aeroelastic behavior of the low aspect ratio wing in the hypersonic regime reveals several interesting results. Figure 17 shows the results for the low aspect ratio wing using first and third order piston theory $\left(M_{f}=23.8\right.$, and $M_{f}=13.5$ respectively). In both cases there is a coalescence of the first and second natural frequencies of the wing with increasing Mach number, during which the first mode begins to approach zero damping. However, despite the similar trends in damping and frequency, the critical Mach number is over predicted by nearly $80 \%$ when using first order piston theory. This discrepancy is associated with the neglect of thickness in first order piston theory. Figure 18 shows the aeroelastic behavior of the wing when using Euler aerodynamics $\left(M_{f}=13.8\right)$. Comparisons of these results with the aeroelastic behavior using third order piston theory aerodynamics illustrates remarkable similarities. While the damping is somewhat different between the two models below $M=12.0$, both produce similar damping levels beyond $M=12.0$ to flutter. However, the Euler simulation predicts that the second mode approaches zero damping first, while for piston theory the first mode loses damping. Both models predict nearly identical changes in frequency of the modes as the Mach number is increased. Also, for both cases there is a coalescence of the first and second modal frequencies with increasing Mach number, while the third to fifth modal frequencies are independent of Mach number. Also, the third to fifth modal damping values are relatively independent of Mach number. It is interesting to note that the difference in flutter boundaries between Euler and piston theory for the wing is merely $2 \%$, while the difference between these two calculations for the two-dimensional configurations was $20-25 \% .{ }^{24}$ It is interesting to note that, for the case of the three-dimensional wing, using Euler aerodynamics results in a higher value of $M_{f}$ when compared to third order piston theory. While from the two-dimensional results, the Euler loads produced a value of $M_{f}$ lower than that obtained from piston theory.

Figure 19 illustrates the aeroelastic behavior of the low aspect ratio wing in the transonic regime at sea level, since this is the most critical loading case. It is evident that the wing is stable throughout the transonic regime. However, it should be noted that while the modal frequencies of the system remain relatively unchanged, there is an initial increase in stability at $M=0.9$ when compared to $M=0.5$, followed 
by a decrease in stability as the Mach number increases to $M=1.2$. In particular, the second to fifth modes seem to have lower levels of damping throughout the transonic regime when compared to the values at $M$ $=0.5$. While the first and second modes have an initial decrease in damping levels as the Mach number is increased from the transonic regime to $M=1.2$, an additional increase in Mach number to $M=1.5$ does not result in a further decrease in damping. These results suggest that the wing is stable through the transonic regime up to the supersonic regime.

Finally, it should be mentioned that aeroelastic results for the low aspect ratio wing using the NavierStokes solver in CFL3D are currently in progress.

\section{B. Aerothermoelastic Behavior of the Low Aspect Ratio Three-Dimensional Wing}

A realistic model for the hypersonic regime must include aerodynamic heating effects. Aerodynamic heating significantly alters the flow properties, ${ }^{46}$ degrades the material properties and also introduces thermal stresses. ${ }^{47-49}$ Aerodynamic heating of the surrounding airflow leads to significantly different thermodynamic and transport properties, high heat-transfer rates, variable $\gamma$, possible ionization, and nonadiabatic effects from radiation. ${ }^{46,47}$ Thermal stresses can arise from rapidly changing conditions of heat input where time lags are involved, or from equilibrium conditions of non-uniform temperature distribution. ${ }^{48,49}$ Commonly, the heated structure has lowered stiffness due to material degradation and thermal stresses, which manifests themselves as a reduction in frequencies. ${ }^{48-50}$

An accurate treatment of aerothermoelasticity requires the coupling of the unsteady heat transfer problem with the aeroelastic problem based on the Navier-Stokes solution of the unsteady airloads. Instead of dealing with this formidable problem, the results presented here are exploratory and are focused on gaining a basic understanding of the importance of this effect. Therefore, approximate calculations are carried out by considering the effect of non-uniform elevated temperatures on the structural stiffness, associated frequencies, and mode shapes.

Again, the low aspect ratio cantilevered wing is a convenient example for studying the effects of aerodynamic heating. For such a configuration the restrained warping at the root of the wing will induce thermal stresses which in turn will affect the torsional stiffness of the wing and modify its frequencies and mode shapes. The effect of warping restraint increases as the aspect ratio of a structure diminishes. ${ }^{51}$ Early studies of this effect ${ }^{52}$ indicate that by modeling a low aspect ratio wing as a plate, the effect of warping restraint is inherently included. More recently, this effect has been studied in the context of composites. ${ }^{53,54}$ In these studies, it has been pointed out that warping restraint is not only important for low-aspect ratio metallic structures, but also for composite structures where the material proprieties are non-isotropic. Furthermore, it was shown that the warping stiffness of a cantilever plate was a function of both aspect ratio, and the ratio of bending/torsion stiffness. ${ }^{1,53}$ This observation is important for hypersonic vehicles where structural properties are altered by aerodynamic heating.

As a first approximation of the effects of aerodynamic heating, a simple aerothermoelastic study has been conducted by assuming a steady nonuniform temperature distribution, that varies with Mach number. This temperature distribution is used to calculate the changes in stiffness and mode shapes associated with the low aspect ratio wing. Two factors induce the changes: (a) degradation of the modulus of elasticity with temperature, and (b) thermal stresses. The thermal stresses are computed with MSC.NASTRAN.

Since the low aspect ratio wing has a double-wedge cross-section, it is assumed that the temperature distribution due to aerodynamic heating has a parabolic shape with peaks located at the leading and trailing edges, and a minimum at mid-chord; ${ }^{55}$ as shown in Fig. 20. To examine the effect of heating on the modes the assumed temperature distribution is normalized by $T_{R E F}$, and the reference temperature is varied. The heated modes and frequencies of the wing are determined using the "Nonlinear Statics Solution" in MSC.NASTRAN (Sol 106 ${ }^{56}$ ) with the normal modes option selected. Data on the dynamic modulus of elasticity for various alloys, including the 2024-T3 Aluminum alloy used in the present study, is given in Ref. 57. The changes in the natural frequencies of the low aspect ratio wing due to the combined effect of thermal stresses and reduction of Young's modulus are shown in Fig. 21. As expected, each of the natural frequencies decrease with decreasing temperature. It is interesting that the fourth mode experiences a large reduction in frequency over a relatively small temperature range $\left(230^{\circ}<T_{R E F}<240^{\circ}\right)$, suggesting the occurrence of thermal buckling. Furthermore, after a smooth decline in frequency until $T_{R E F}=200^{\circ}$, the frequencies of all the modes change discontinuously as the temperature is incremented further. Since thermal stresses are present in the structure, it is important to study changes in the mode shapes as a function of increasing temperature. The mode shapes at $T_{R E F}=200^{\circ}, T_{R E F}=232^{\circ}$ and $T_{R E F}=281^{\circ}$ are shown in Figs. 22 , 23 , and 24 respectively. Around $T_{R E F}=200^{\circ}$, a large wrinkle appears in each of the modes near the root at the leading and trailing edges of the wing. Furthermore, comparing these mode shapes with the baseline modes shown in Fig. 16 illustrates that the fourth mode has changed in character from a torsional mode, to a mode where the deformation takes place locally near the root of the trailing edge. A further increase in temperature results in similar mode shapes between the third and fourth modes. Furthermore, the wrinkling of the leading and trailing edges has propagated further out towards the wing tip. It is important to note that these plots are only snapshots at a given temperature, and therefore may not be representative of the broad changes in mode shapes that takes place throughout the temperature spectrum. These figures indicate that 
further study is needed in order to develope an improved understanding for the combined effect of thermal stresses and non-uniform temperature changes on the modal behavior of low aspect ratio wings.

An aerothermoelastic study with modified mode shapes requires a relation between the reference temperature, $T_{R E F}$ and flow Mach number for the low aspect ratio wing. This relationship is predicated on the existence of a thermal protection system (TPS). The assumed TPS provides a linear increase in temperature from $200^{\circ} \mathrm{F}$ at $M=3.5$ to $350^{\circ} \mathrm{F}$ at $M=10.0$. Above $M=10.0$, the TPS loses effectiveness and the temperature increases such that it is proportional to the adiabatic wall temperature, reaching a temperature of $1000^{\circ} \mathrm{F}$ at $M=20.0$. This variation is described by,

$$
\begin{array}{rlr}
T_{R E F} & =f_{1}(M) & \\
& =200+23.08(M-3.5) & 2 \leq M \leq 10 \\
& =318.12+4.19(M-7.25)^{2} & 10<M \leq 20
\end{array}
$$

and it is depicted in Fig. 25.

Using this relationship between Mach number and reference temperature, the modes and frequencies are calculated at a given Mach number. Piston theory aerodynamics is used in conjunction with these heated modes and frequencies to determine aeroelastic damping and frequency characteristics at an altitude of 40,000 ft. The resulting flutter boundary for the heated low aspect ratio wing is shown in Fig. 26. It is evident that the heating of the structure has a dramatic effect on the flutter boundary of the wing. The dramatic drop in frequency of the fourth mode around $M=5.0\left(T_{R E F}=235^{\circ}\right)$ resulted in an instantaneous loss of stability in the system. Even with a small step in Mach number and temperature, no damping or frequency characteristics could be calculated as the Mach number approached $M=5.0$, as illustrated by the lack of values through this range of Mach number. However, as the temperature and Mach number was increased past $M=5.25\left(T_{R E F}=240^{\circ}\right)$ stability was regained until $M=9.0\left(T_{R E F}=327^{\circ}\right)$. Comparing these results to the baseline case shown in Fig. $17\left(M_{f}=13.8\right)$ illustrates a large reduction in aeroelastic stability when the wing is heated. These results demonstrate the importance of correctly modeling aerodynamic heating on a flexible structure. Further study of this topic is in progress.

\section{Aeroelastic Behavior of a Generic Reusable Launch Vehicle}

The model employed in this study is a vehicle that resembles a generic reusable launch vehicle. It consists of a lifting body and canted fins, shown in Fig. 27. The dimensions of the generic vehicle are $76.2 \mathrm{ft}$. length, $45.54 \mathrm{ft}$. width, and $6 \mathrm{ft}$. thickness. The canted fins have a span of $18 \mathrm{ft}$. with a taper ratio of 0.25 . They have double-wedge cross-sections with the maximum thickness at mid-chord, equal to $3.33 \%$ of the chord. The empty mass of the vehicle is considered to be 70,000 lbs. The unrestrained modes were obtained using MSC.NASTRAN. The first five modes are depicted in Fig. 28. The first two modes are the symmetric and antisymmetric fin bending modes, while the third and fourth modes show fuselage bending and fuselage torsion. The fifth and higher modes show a combination of fin and fuselage deformation.

In previous hypersonic studies, the approximate aerodynamic method of choice for bluff bodies has been Newtonian impact theory blended with piston theory. ${ }^{16,58}$ The generic vehicle, shown in Fig. 27, has sharp leading edges. For $M>5$, the wedge angles are small enough to allow the presence of attached oblique shocks. However, the wedge angles are large and $M \delta \gg 1$, hence, instead of using a blended approach, a different approach, described next, is used.

The geometry of the generic hypersonic vehicle usually consists of a combination of flat surfaces having different wedge angles to the oncoming flow. In regions around the nose, and at the rear of the vehicle, the actual slope might be different due to localized curvature of the geometry. Since piston theory is a twodimensional theory which relates parameters in the $x-z$ plane, a sectional model of the vehicle can be created using piston theory alone. Fig. 29 shows that the streamlines along the surface in an inviscid flow have relatively small flow velocity components in the spanwise direction. Furthermore, at these Mach numbers, only a small portion at the root of the fin is affected by the flow around the fuselage (body). Therefore, the flow over the fins is assumed to be free-stream in this model. Thus, the surface of the vehicle can be divided into "flow zones", where the flow variables have substantially different values, due to the presence of oblique shocks and expansion fans. The local flow variables can thus be calculated at various points on the surface of the rigid geometry. Assuming small perturbations during the unsteady aeroelastic analysis, these values need not be recalculated, saving computational effort. Next, an unsteady aeroelastic analysis is carried out using piston theory with these local variables, applied in frames rotated to the angles of the flat surfaces approximating the fuselage.

Using linear and nonlinear piston theory, the aeroelastic behavior of the generic hypersonic vehicle was studied at different altitudes. The flutter Mach number, $M_{f}$, was calculated at 40,000 feet using nonlinear piston theory with a varying number of structural modes. The results given in Table 14 indicate that the minimum number of modes required for a converged solution is 12 . The aeroelastic behavior of the generic hypersonic vehicle at this altitude using linear piston theory is shown in Fig. 30, and that using nonlinear piston theory is shown in Fig. 31. At this altitude, the linear model predicts $M_{f}=13.2$, while the nonlinear model predicts $M_{f}=7.1$; thus, the linear model overpredicts the nonlinear model by $86 \%$. For the nonlinear model, flutter occurs due to an interaction between the modes with significant fin bending, i.e. the higher 
frequency modes. The body modes, i.e. the third (fuselage-bending) and fourth (fuselage-torsion) modes, do not contribute to flutter. However, the linear model indicates that flutter initiates from an interaction between modes numbered 2, 5 and 10 . When the altitude is increased to 50,000 feet, nonlinear piston theory predicts $M_{f}=9.7$, as seen in Fig. 32, and flutter still arises from an interaction of the higher modes with significant fin bending.

Studies are also being carried out on the aeroelastic behavior of the generic vehicle using Euler and Navier-Stokes based unsteady aerodynamic loads to determine the influence of viscosity on the aeroelastic stability boundaries. Results for the generic hypersonic vehicle will constitute an important contribution to the state of the art, since there are no results available for hypersonic vehicle aeroelasticity using complete solutions of the unsteady Navier-Stokes equations.

\section{Conclusions}

The studies carried out in this paper support, the following conclusions. These conclusions are limited by the various assumptions made.

1. For three-dimensional configurations, efficient distribution of the mesh points around the body is critical due to limits in computational resources. For hypersonic flow, the computational domain should not extend far beyond the body, with the majority of points placed close to the surface. This also implies that the same grid can be used for Euler and Navier-Stokes aerodynamics.

2. The flutter Mach number of the low aspect ratio wing can be over predicted by as much as $80 \%$ when using first order piston theory compared to third order piston theory.

3. Stability boundaries of the three-dimensional low aspect ratio wing predicted by Euler solutions are approximately $2 \%$ higher than those predicted by piston theory.

4. The presence of aerodynamic heating on a low aspect ratio cantilever structure, such as a fin and/or control surface on a hypersonic vehicle, will result in thermal stresses due to warping restraint at the root. This, combined with material property degradation, dramatically affects the mode shapes and natural frequencies of the structure and significantly reduces the flutter Mach number.

5. The aeroelastic behavior of the generic hypersonic vehicle predicted by linear and nonlinear piston theory is found to be qualitatively similar, though the linear model overpredicts the flutter boundary by $86 \%$. Flutter for the generic hypersonic vehicle is seen to arise from the convergence of modes having significant fin bending.

6. It is apparent that as the Mach number becomes large, there are significant differences between first order and third order piston theory, independent of structural configuration studied. Therefore, predictions of aeroelastic stability based on linear piston theory can be unreliable, and the boundaries are not conservative.

7. The results presented can be considered to provide a partial validation of the aeroelastic capabilities of the CFL3D code for the hypersonic flow regime.

\section{Acknowledgement}

The authors wish to express their gratitude to NASA Langley Research Center for the CFL3D code and thank Dr. R. Biedron for their help in using this code. This research has benefited from partial support from several sources, AFOSR grant F49620-01-0158 with Dr. D. Mook as program manager, NASA Dryden training grant NCT4-52426 (to J. McNamara) and NASA URETI award NCC 3989 funded by NASA Marshall and Glenn Research Centers.

\section{References}

[1] Bisplinghoff, R.L. and Dugundji, J., Influence of Aerodynamic Heating on Aeroelastic Phenomena in High Temperature Effects in Aircraft Structures, Agardograph No. 28, Edited by N.J. Hoff, Pergamon Press, 1958, pp. 288-312.

[2] Garrick, I.E., "A Survey of Aerothermoelasticity," Aerospace Engineering, January, 1963, pp. 140-147. 
[3] Hedgepeth, J. and Widmayer, E., "Dynamic and Aeroelastic Problems of LIfting Re-Entry Bodies," Aerospace Engineering, January, 1963, pp. 148-153.

[4] Laidlaw, W.R. and Wyker, J.H., "Potential Aerothermoelastic Problems Associated with Advanced Vehicle Design," Aerospace Engineering, January, 1963, pp. 154-164.

[5] Xue, D.Y. and Mei, C., "Finite Element Two-Dimensional Panel Flutter at High Supersonic Speeds and Elevated Temperature," AIAA Paper No. 90-0982, Proc. 31st AIAA/ASME/ASCE/AHS/ASC Structures, Structural Dynamics and Materials Conference, 1990, pp. 1464-1475.

[6] Gray, E.G. and Mei, C., "Large-Amplitude Finite Element Flutter Analysis of Composite Panels in Hypersonic Flow," AIAA Paper No. 92-2130, Proc. 33rd AIAA/ASME/ASCE/AHS/ASC Structures, Structural Dynamics and Materials Conference, Dallas, TX, April 16-17 1992, pp. 492-512.

[7] Abbas, J.F. and Ibrahim,R.A., "Nonlinear Flutter of Orthotropic Composite Panel Under Aerodynamic Heating," AIAA J., Vol. 31, No. 8, No. 8, 1993, pp. 1478-1488.

[8] Bein, T., Friedmann, P., Zhong, X., and Nydick, I., "Hypersonic Flutter of a Curved Shallow Panel with Aerodynamic Heating," AIAA Paper No. 93-1318, Proc. 34th AIAA/ASME/ASCE/AHS/ASC Structures, Structural Dynamics and Materials Conference, La Jolla, CA, April 19-22 1993.

[9] Nydick, I., Friedmann, P.P., and Zhong, X., "Hypersonic Panel Flutter Studies on Curved Panels," AIAA Paper no. 95-1485, Proc. 36th AIAA/ASME/ASCE/AHS/ASC Structures, Structural Dynamics and Materials Conference, New Orleans, LA, April 1995, pp. 2995-3011.

[10] Mei, C., Abdel-Motagly, K., and Chen, R., "Review of Nonlinear Panel Flutter at Supersonic and Hypersonic Speeds," Applied Mechanics Reviews, 1998.

[11] Ricketts, R., Noll, T., Whitlow, W., and Huttsell,L., "An Overview of Aeroelasticity Studies for the National Aerospace Plane," AIAA Paper No. 93-1313, Proc. 34th AIAA/ASME/ASCE/AHS/ASC Structures, Structural Dynamics and Materials Conference, La Jolla, CA, April 19-22 1993, pp. 152 - 162.

[12] Spain, C., Zeiler, T.A., Bullock, E., and Hodge, J.S., "A Flutter Investigation of All-Moveable NASP-Like Wings at Hypersonic Speeds," AIAA Paper No. 93-1315, Proc. 34th AIAA/ASME/ASCE/AHS/ ASC Structures, Structural Dynamics and Materials Conference, La Jolla, CA, April 19-22 1993.

[13] Scott, R.C. and Pototzky, A.S., "A Method of Predicting Quasi-Steady Aerodynamics for Flutter Analysis of High Speed Vehicles Using Steady CFD Calculations," AIAA Paper No. 93-1364, Proc. 34th AIAA/ASME/ASCE/AHS/ASC Structures, Structural Dynamics and Materials Conference, La Jolla, CA, April 19-22 1993, pp. 595603.

[14] Spain, C., Zeiler, T.A., Gibbons, M.D., Soistmann, D.L., Pozefsky, P., DeJesus, R.O., and Brannon,C.P., "Aeroelastic Character of a National Aerospace Plane Demonstrator Concept," Proc. 34th AIAA/ASME/ASCE/AHS/ ASC Structures, Structural Dynamics and Materials Conference, La Jolla, CA, April 19-22 1993, pp. 163-170.

[15] Rodgers, J.P., "Aerothermoelastic Analysis of a NASP-Like Vertical Fin," AIAA-92-2400-CP, Proc. 33rd AIAA/ASME/ASCE/AHS Structures, Structural Dynamics and Materials Conference, Dallas, TX, April 1992.

[16] Heeg, J., Zeiler, T., Pototzky, A., Spain, C., and Engelund, W., "Aerothermoelastic Analysis of a NASP Demonstrator Model," AIAA Paper No. 93-1366, Proc. 34th AIAA/ASME/ASCE/AHS/ASC Structures, Structural Dynamics and Materials Conference, La Jolla, CA, April 19-22 1993, pp. 617-627.

[17] Heeg, J. and Gilbert, M.G., "Active Control of Aerothermoelastic Effects for a Conceptual Hypersonic Aircraft," Journal of Aircraft, Vol. 30, 1993, pp. 453-458.

[18] Blades, E., Ruth, M., and Fuhrman, D., "Aeroelastic Analysis of the X-34 Launch Vehicle," AIAA Paper No. 99-1352, Proc. 40th AIAA/ASME/ASCE/AHS/ ASC Structures, Structural Dynamics and Materials Conference, St. Louis, MO, 1999, pp. 1321-1331.

[19] Nydick, I. and Friedmann, P.P., "Aeroelastic Analysis of a Generic Hypersonic Vehicle," NASA/CP1999-209136/PT2, Proc. CEAS/AIAA/ICASE/NASA Langley International Forum on Aeroelasticity and Structural Dynamics, Williamsburg, VA, June 22-25 1999, pp. 777-810.

[20] Gupta, K.K., Voelker, L.S., Bach, C., Doyle, T., and Hahn, E., "CFD-Based Aeroelastic Analysis of the X-43 Hypersonic Flight Vehicle," AIAA Paper No. 2001-0712, 39th Aerospace Sciences Meeting \& Exhibit, 2001. 
[21] Berry, S.A., Horvath, T.J., Hollis, B.R., Thompson, R.A., and Hamilton, H.H., "X-33 Hypersonic Boundary Layer Transition," AIAA Paper No. 99-3560, 33rd AIAA Thermophysics Conference, Norfolk, VA, June 28 - July 11999.

[22] Riley, C.J., Kleb, W.L., and Alter, S.J., "Aeroheating Predictions for X-34 Using An Inviscid-Boundary Layer Method," AIAA 98-0880, 36th Aerospace Sciences Meeting $\&$ Exhibit, Reno, NV, January 1998.

[23] Thuruthimattam, B.J., Friedmann, P.P., McNamara, J.J., and Powell, K.G., "Aeroelasticity of a Generic Hypersonic Vehicle," AIAA Paper No. 2002-1209, Proc. 43rd AIAA/ASME/ASCE/AHS Structures, Structural Dynamics and Materials Conference, Denver, CO, April 2002.

[24] Thuruthimattam, B.J., Friedmann, P.P., McNamara, J.J., and Powell, K.G., "Modeling Approaches to Hypersonic Aerothermoelasticity with Application to Resuable Launch Vehicles," AIAA Paper No. 20031967, Proc. 44th AIAA/ASME/ASCE/AHS Structures, Structural Dynamics and Materials Conference, Norfolk, VA, April 2003.

[25] Krist, S.L., Biedron, R.T., and Rumsey, C.L., "CFL3D User's Manual (Version 5.0)," NASA, TM 1998-208444, 1997.

[26] Robinson, B.A., Batina, J.T., and Yang, H.T., "Aeroelastic Analysis of Wings Using the Euler Equations with a Deforming Mesh," Journal of Aircraft, Vol. 28, November 1991, pp. 778-788.

[27] Cunningham, H.J., Batina, J.T., and Bennett, R.M., "Modern Wing Flutter Analysis by Computational Fluid Dynamic Methods," Journal of Aircraft, Vol. 25, No. 10, No. 10, 1989, pp. 962-968.

[28] Lee-Rausch, E.M. and Batina, J.T., "Wing Flutter Boundary Prediction Using Unsteady Euler Aerodynamic Method," AIAA Paper No. 93-1422, Proc. 34th AIAA/ASME/ASCE/AHS Structures, Structural Dynamics and Materials Conference, 1993, pp. 1019-1029.

[29] Lee-Rausch, E.M. and Batina, J.T., "Calculation of AGARD Wing 445.6 Flutter Using Navier-Stokes Aerodynamics," AIAA Paper No. 93-3476, Proc. AIAA 11th Applied Aerodynamics Conference, Hampton, VA, August 9-11 1993.

[30] Batina, J.T., "Unsteady Euler Airfoil Solutions Using Unstructured Dynamic Meshes," AIAA Journal, Vol. 28, 1990, pp. 1381-1388.

[31] Hughes, T.J.R. and Hulbert, G.M., "Space-Time Finite Element Methods For Elastodynamics: Formulations and Error Estimates," Computer Methods in Applied Mechanics and Engineering, Vol. 66, 1988, pp. 339-363.

[32] Tezduyar, T.E., Behr, M., and Liou, J., "A New Strategy for Finite Element Computations involving Moving Boundaries and Interfaces - The Deforming-spatial-domain/Space-time Procedure: I. The concept and the Preliminary Numerical Tests," Computer Methods in Applied Mechanics and Engineering, Vol. 94, 1992, pp. 339-351.

[33] Tezduyar, T.E., Behr, M., and Liou, J., "A New Strategy for Finite Element Computations involving Moving Boundaries and Interfaces - The Deforming-spatial-domain/Space-time Procedure: I. Computation of Free-surface Flows, Two-liquid Flows, and Flows with Drifting Cylinders," Computer Methods in Applied Mechanics and Engineering, Vol. 94, 1992, pp. 353-371.

[34] Donea, J., Guiliani, S., and Halleux, J.P., "An Arbitrary Lagrangian-Eulerian Finite Element Method for Transient Dynamic Fluid-Structure Interactions," Computer Methods in Applied Mechanics and Engineering, Vol. 33, 1982, pp. 689-723.

[35] Bendiksen, O.O., "A New Approach to Computational Aeroelasticity," Proc. AIAA/ASME/ASCE/AHS/ASC 32nd Structure, Structural Dynamics and Materials Conf., Baltimore, MD, April 8-9 1991, pp. 1712-1727. AIAA Paper 91-0939.

[36] Farhat, C., Lesoinne, M., and Maman, N., "Mixed Explicit/Implicit Time Integration of Coupled Aeroelastic Problems: Three-field Formulation, Geometric Conservation and Distributed Solution," International Journal for Numerical Methods in Fluids, Vol. 21, 1995, pp. 807-835.

[37] Tran H. and Farhat, C., "An Integrated Platform for the Simulation of Fluid-Structure-Thermal Interaction Problems," AIAA Paper No. 2002-1307, Proc. 43rd AIAA/ASME/ASCE/AHS Structures, Structural Dynamics and Materials Conference, Denver, CO, April 2002.

[38] Stephens, C.H., Arena Jr., A.S., and Gupta, K.K., "Application of the transpiration method for aeroservoelastic prediction using CFD," AIAA Paper 98-2071, Proceedings of the 39th AIAA/ASME/ASCE/AHS/ASC Structures, Structural Dynamics, and Materials Conference and Exhibit, Long Beach, CA, April 20-23 1998. 
[39] Bousman, W.G. and Winkler, D.J., "Application of the Moving-Block Analysis," AIAA 81-0653, Proceedings of the AIAA Dynamics Specialist Conference, Atlanta, GA, April 1981, pp. 755-763.

[40] Chen, P.C. and Liu, D.D., "Unified Hypersonic/Supersonic Panel Method for Aeroelastic Applications to Arbitrary Bodies," Journal of Aircraft, Vol. 39, No. 3, No. 3, 2002, pp. 499-506.

[41] Liu, D.D., Chen, P.C., Tang, L., Chang, K.T., and Gao, X.W., "Expedient Hypersonic Aerothermodynamics Methodology for RLV/TPS Design," Proc. 11th AIAA/AAAF International Conference on Space Planes and Hypersonic Systems and Technologies, Orleans, France, September 2002.

[42] Anderson, J.D., Hypersonic and High Temperature Gas Dynamics, New York, McGraw-Hill, 1989.

[43] Rasmussen, M., Hypersonic Flow New York, John Wiley \& Sons, 1994.

[44] Ashley, H. and Zartarian, G., "Piston Theory - A New Aerodynamic Tool for the Aeroelastician," Journal of the Aeronautical Sciences, Vol. 23, No. 12, No. 12, 1956, pp. 1109-1118.

[45] Lighthill, M.J., "Oscillating Airfoils at High Mach Numbers," Journal of the Aeronautical Sciences, Vol. 20, No. 6, June 1953.

[46] Anderson, J.D., Aerothermodynamics: A Tutorial Discussion in Thermal Structures and Materials for High-speed Flight, AIAA, 1992, Ch. 1, pp. 3-57.

[47] Bisplinghoff, R.L., "Some Structural and Aeroelastic Considerations of High-Speed Flight," Journal of the Aerospace Sciences, Vol. 23, No. 4, April 1956, pp. 289-329.

[48] Rogers, M., "Aerothermoelasticity," AeroSpace Engineering, October 1958, pp. 34-43.

[49] Garrick, I.E., "Aeroelasticity Effects of High Temperatures," Aerospace Engineering, January 1963, pp. 140-147.

[50] Budiansky, B. and Mayers, J., "Influence of Aerodynamic Heating on the Effective Torsional Stiffness of Thin Wings," Journal of the Aeronautical Sciences, December 1956, pp. 1081-1093.

[51] Bisplinghoff, R.L., Ashley, H., and Halfman, R.L., Aeroelasticity, Addison-Wesley, 1955.

[52] Reissner, E. and Stein M., "Torsion and Transverse Bending of Cantilever Plates," NACA, TN 2369, 1951.

[53] Crawley, E.F. and Dugundji, J., "Frequency Determination and Non-Dimensionalization for Composit Cantilever Plates," Journal of Sound and Vibration, Vol. 72, No. 1, No. 1, 1980, pp. 1-10.

[54] Gern, F. and Librescu, L., "Aeroelastic Tailoring of Composite Wings Exhibiting Nonclassical Effects and Carrying External Stores," Journal of Aircraft, Vol. 37, No. 6, No. 6, 2000, pp. 1097-1104.

[55] Runyan, H.L. and Jones, N.H., "Effect of Aerodynamic Heating on the Flutter of a Rectangular Wing at a Mach Number of 2," NACA, TN RM L58C31, 1958.

[56] "MSC.NASTRAN Reference Manual," 2001.

[57] Vosteen, L.F., "Effect of Temperature on Dynamic Modulus of Elasticity of Some Structural Alloys," NACA, TN 4348, August 1958.

[58] Nydick, I., "Studies in Hypersonic Aeroelasticity," Ph.D. Dissertation, University of California, Los Angeles, 2000.

Table 1: Grid resolutions of each test case.

\begin{tabular}{|c|c|}
\hline \# of Cells & Mesh \\
\hline \hline $4.0 \times 10^{6}$ & MESH1 \\
$0.63 \times 10^{6}$ & MESH2 \\
$0.63 \times 10^{6}$ & MESH3 \\
$0.63 \times 10^{6}$ & MESH4 \\
\hline
\end{tabular}


Table 2: Effect of grid resolution on the accuracy of $C_{L}$ computations using Euler aerodynamics.

\begin{tabular}{|c|c|c|}
\hline \# of Cells & $M=5.0$ & $M=16.0$ \\
\hline \hline $0.08 \times 10^{6}$ & $0.70 \%$ & $3.09 \%$ \\
$0.27 \times 10^{6}$ & $0.74 \%$ & $1.53 \%$ \\
$0.63 \times 10^{6}$ & $0.67 \%$ & $1.11 \%$ \\
$2.1 \times 10^{6}$ & $0.23 \%$ & $0.44 \%$ \\
$5.1 \times 10^{6}$ & N/A & N/A \\
\hline
\end{tabular}

Table 3: Effect of grid resolution on the accuracy of $C_{M}$ computations using Euler aerodynamics.

\begin{tabular}{|c|c|c|}
\hline \# of Cells & $M=5.0$ & $M=16.0$ \\
\hline \hline $0.08 \times 10^{6}$ & $1.84 \%$ & $3.16 \%$ \\
$0.27 \times 10^{6}$ & $0.96 \%$ & $1.84 \%$ \\
$0.63 \times 10^{6}$ & $0.10 \%$ & $1.29 \%$ \\
$2.1 \times 10^{6}$ & $0.24 \%$ & $0.43 \%$ \\
$5.1 \times 10^{6}$ & N/A & N/A \\
\hline
\end{tabular}

Table 4: $L_{2}$ norm of $\frac{p}{p_{\infty}}$ at various grid resolutions using Euler aerodynamics.

\begin{tabular}{|c|c|c|}
\hline \# of Cells & $M=5.0$ & $M=16.0$ \\
\hline \hline $0.08 \times 10^{6}$ & 0.1406 & 0.9047 \\
$0.27 \times 10^{6}$ & 0.0713 & 0.3930 \\
$0.63 \times 10^{6}$ & 0.0784 & 0.6342 \\
$2.1 \times 10^{6}$ & 0.0734 & 0.3838 \\
$5.1 \times 10^{6}$ & N/A & N/A \\
\hline
\end{tabular}

Table 5: $L_{\infty}$ norm of $\frac{p}{p_{\infty}}$ at various grid resolutions using Euler aerodynamics.

\begin{tabular}{|c|c|c|}
\hline \# of Cells & $M=5.0$ & $M=16.0$ \\
\hline \hline $0.08 \times 10^{6}$ & 0.3431 & 2.0672 \\
$0.27 \times 10^{6}$ & 0.1315 & 0.8004 \\
$0.63 \times 10^{6}$ & 0.2715 & 1.9873 \\
$2.1 \times 10^{6}$ & 0.1423 & 0.7716 \\
$5.1 \times 10^{6}$ & N/A & N/A \\
\hline
\end{tabular}

Table 6: Effect of grid resolution on the accuracy of $C_{L}$ computations using Navier-Stokes aerodynamics.

\begin{tabular}{|c|c|c|}
\hline \# of Cells & $M=5.0$ & $M=16.0$ \\
\hline \hline $0.08 \times 10^{6}$ & $0.87 \%$ & $6.78 \%$ \\
$0.27 \times 10^{6}$ & $0.01 \%$ & $4.31 \%$ \\
$0.63 \times 10^{6}$ & $0.73 \%$ & $3.11 \%$ \\
$2.1 \times 10^{6}$ & $0.01 \%$ & $0.95 \%$ \\
$5.1 \times 10^{6}$ & N/A & N/A \\
\hline
\end{tabular}


Table 7: Effect of grid resolution on the accuracy of $C_{M}$ computations using Navier-Stokes aerodynamics.

\begin{tabular}{|c|c|c|}
\hline \# of Cells & $M=5.0$ & $M=16.0$ \\
\hline \hline $0.08 \times 10^{6}$ & $7.40 \%$ & $2.87 \%$ \\
$0.27 \times 10^{6}$ & $2.87 \%$ & $3.06 \%$ \\
$0.63 \times 10^{6}$ & $1.49 \%$ & $2.32 \%$ \\
$2.1 \times 10^{6}$ & $4.94 \%$ & $0.36 \%$ \\
$5.1 \times 10^{6}$ & N/A & N/A \\
\hline
\end{tabular}

Table 8: Effect of grid resolution on the accuracy of $C_{D}$ computations using Navier-Stokes aerodynamics.

\begin{tabular}{|c|c|c|}
\hline \# of Cells & $M=5.0$ & $M=16.0$ \\
\hline \hline $0.08 \times 10^{6}$ & $24.6 \%$ & $79.3 \%$ \\
$0.27 \times 10^{6}$ & $5.18 \%$ & $37.9 \%$ \\
$0.63 \times 10^{6}$ & $7.84 \%$ & $27.1 \%$ \\
$2.1 \times 10^{6}$ & $0.04 \%$ & $0.45 \%$ \\
$5.1 \times 10^{6}$ & N/A & N/A \\
\hline
\end{tabular}

Table 9: $L_{2}$ norm of $\frac{p}{p_{\infty}}$ at various grid resolutions using Navier-Stokes aerodynamics.

\begin{tabular}{|c|c|c|}
\hline \# of Cells & $M=5.0$ & $M=16.0$ \\
\hline \hline $0.08 \times 10^{6}$ & 0.6128 & 7.0045 \\
$0.27 \times 10^{6}$ & 0.3794 & 2.6719 \\
$0.63 \times 10^{6}$ & 0.5829 & 7.0423 \\
$2.1 \times 10^{6}$ & 0.3224 & 2.2489 \\
$5.1 \times 10^{6}$ & N/A & N/A \\
\hline
\end{tabular}

Table 10: $L_{\infty}$ norm of $\frac{p}{p_{\infty}}$ at various grid resolutions using Navier-Stokes aerodynamics.

\begin{tabular}{|c|c|c|}
\hline \# of Cells & $M=5.0$ & $M=16.0$ \\
\hline \hline $0.08 \times 10^{6}$ & 1.2862 & 15.3114 \\
$0.27 \times 10^{6}$ & 1.004 & 8.9927 \\
$0.63 \times 10^{6}$ & 1.2820 & 15.4131 \\
$2.1 \times 10^{6}$ & 0.9265 & 8.9043 \\
$5.1 \times 10^{6}$ & N/A & N/A \\
\hline
\end{tabular}


Table 11: Parameters describing the double-wedge airfoil.

\begin{tabular}{|c|c|}
\hline Parameter & Configuration II \\
\hline$c(\mathrm{~m})$ & 2.35 \\
Thickness ratio $(\%)$ & 3.36 \\
Wedge angle $\left(^{\circ}\right)$ & 3.85 \\
$m(\mathrm{~kg} / \mathrm{m})$ & 94.2 \\
$r_{\alpha}$ & 0.484 \\
$\omega_{h}(\mathrm{~Hz})$ & 13.4 \\
$\omega_{\alpha}(\mathrm{Hz})$ & 37.6 \\
$\omega_{h}$ & 0.356 \\
$\omega_{\alpha}$ & 0.2 \\
$x_{\alpha}$ & 0.1 \\
$a$ & \\
\hline
\end{tabular}

Table 12: Comparison of the Lockheed F-104 Starfighter wing to the low aspect ratio wing model

\begin{tabular}{|c|c|c|}
\hline Parameter & F-104 & 3-D Wing \\
\hline Wing Mass (Kg) & 350.28 & 350.05 \\
\hline 1st Bending Frequency (Hz) & 13.40 & 13.41 \\
\hline 1st Torsional Frequency (Hz) & 37.60 & 37.51 \\
\hline
\end{tabular}

Table 13: Flutter results for the low aspect ratio wing using an increasing number of modes, and third order piston theory aerodynamics, at 40,000ft.

\begin{tabular}{|c|c|}
\hline No. of Modes & $M_{f}$ \\
\hline \hline 2 & 15.6 \\
5 & 13.5 \\
8 & 13.3 \\
\hline
\end{tabular}

Table 14: Flutter results for the generic vehicle using an increasing number of modes, and third order piston theory aerodynamics, at 40,000ft.

\begin{tabular}{|c|c|}
\hline No. of modes & $M_{f}$ \\
\hline \hline 7 & 11.6 \\
10 & 7.8 \\
12 & 7.1 \\
14 & 7.1 \\
\hline
\end{tabular}




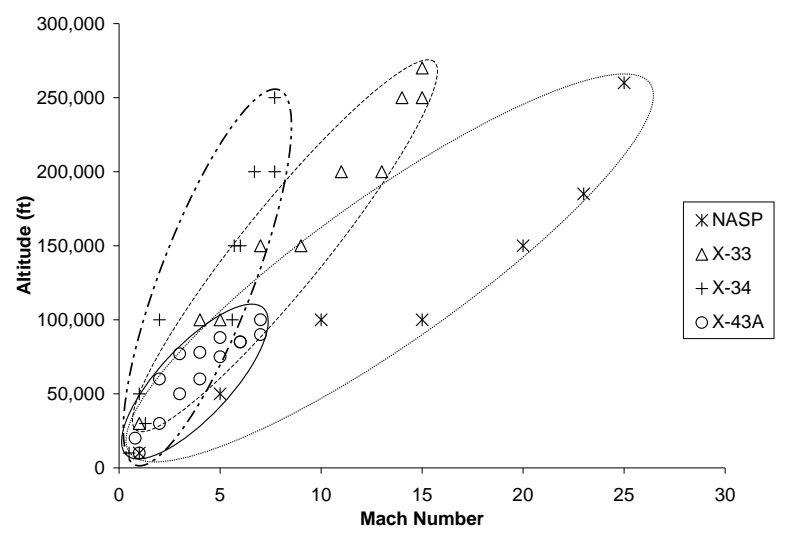

Figure 1: Operating envelopes for several modern hypersonic vehicles.

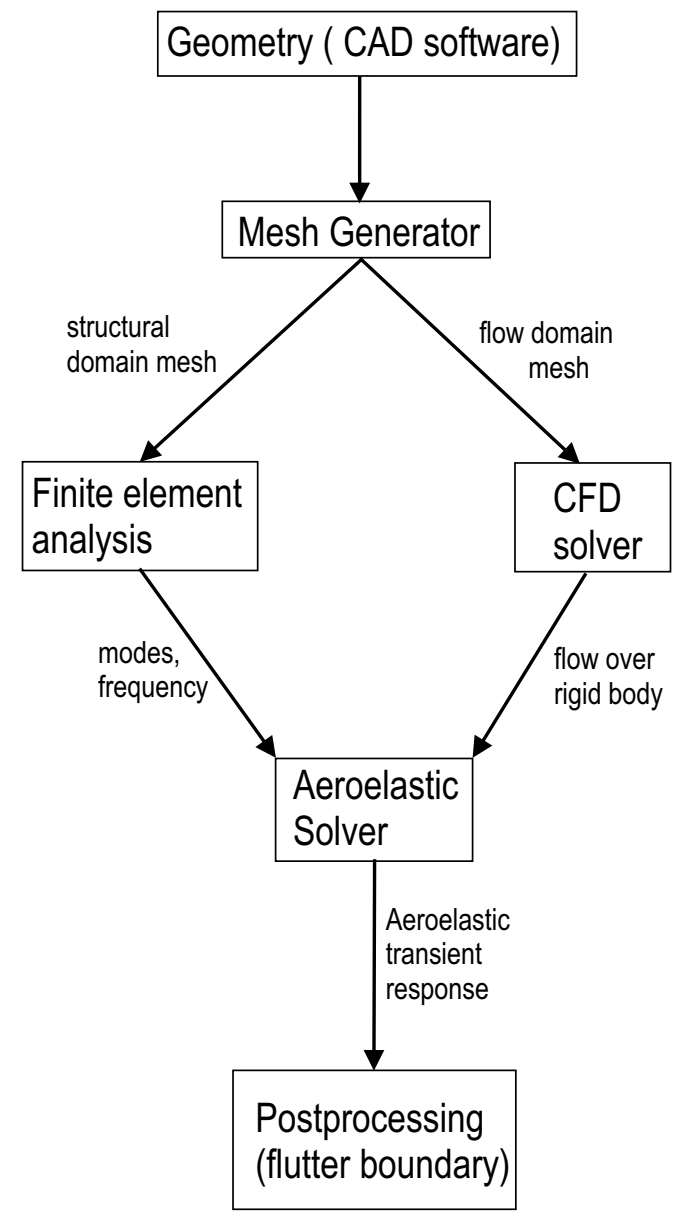

Figure 2: A flow diagram of the computational aeroelastic solution procedure. 


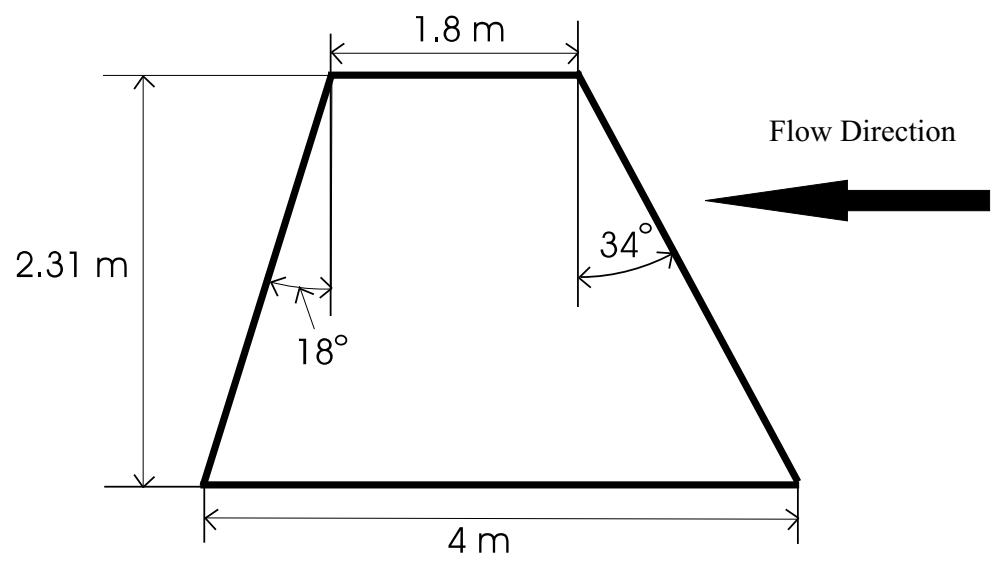

(a) Planform of the low aspect ratio wing.

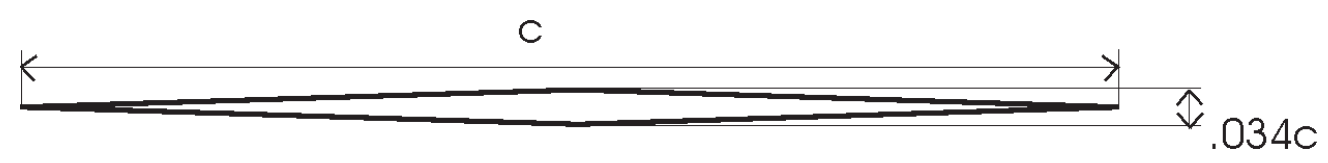

(b) Cross-sectional dimensions of low aspect ratio wing.

Figure 3: A planform view of the low aspect ratio wing and a view of its cross-section.

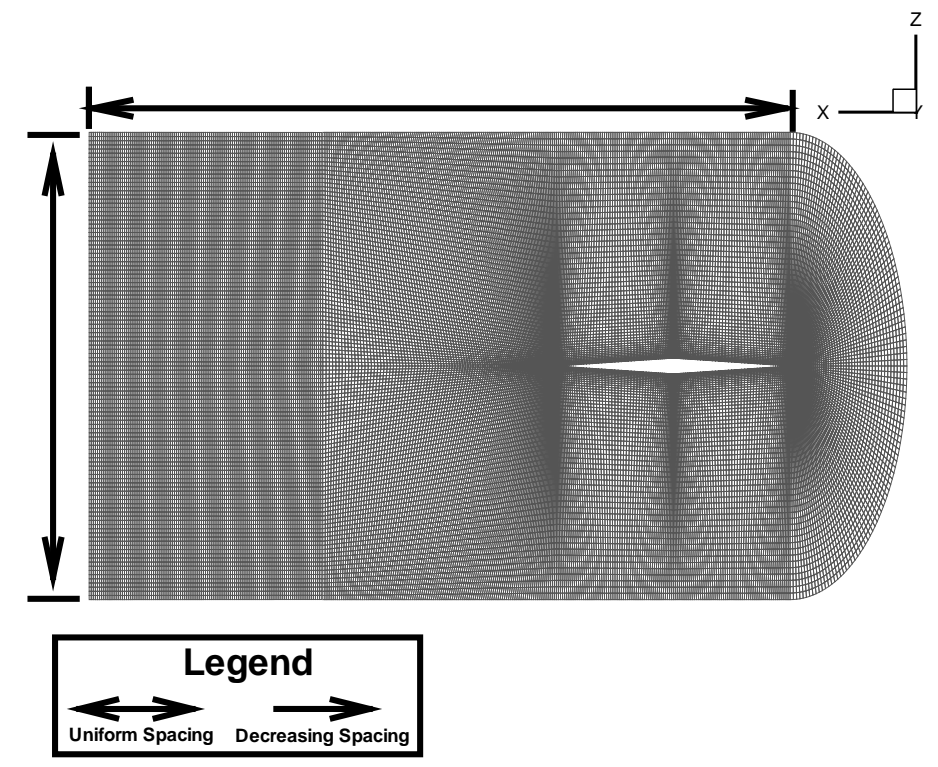

Figure 4: Root plane of MESH1. 


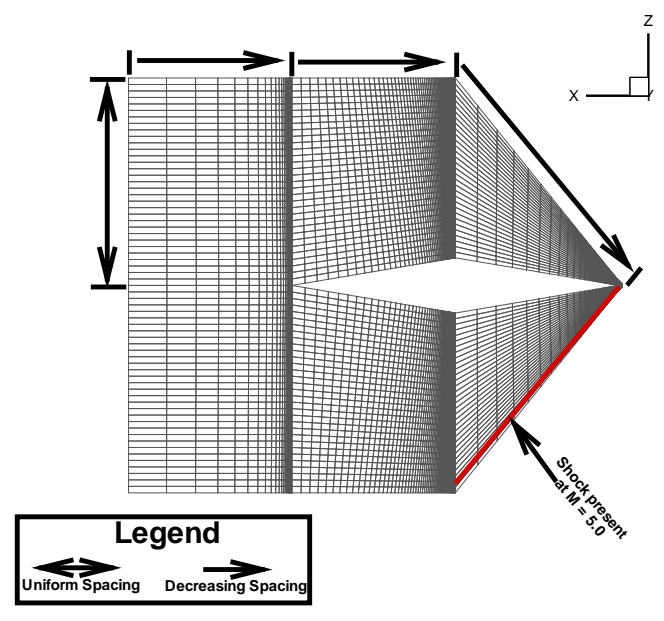

Figure 5: Root plane of MESH2.

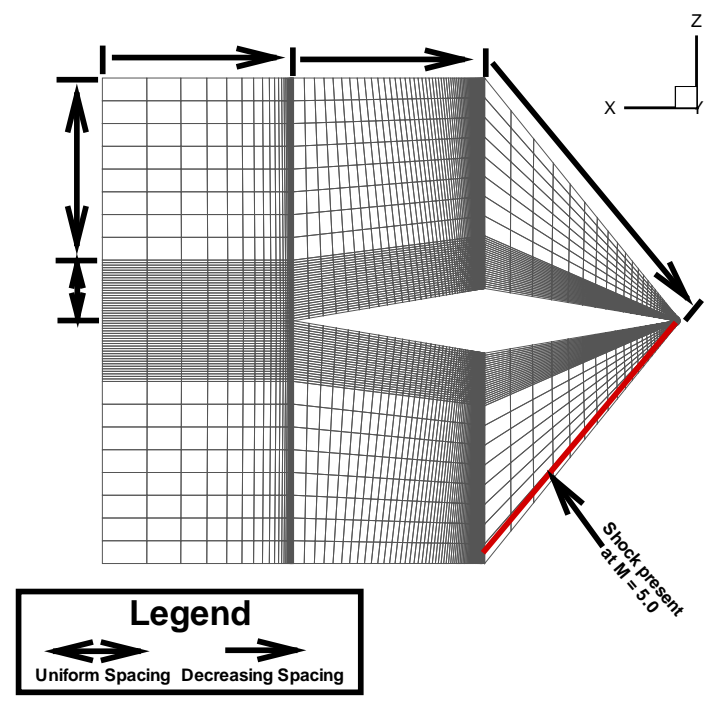

Figure 6: Root plane of MESH3. 


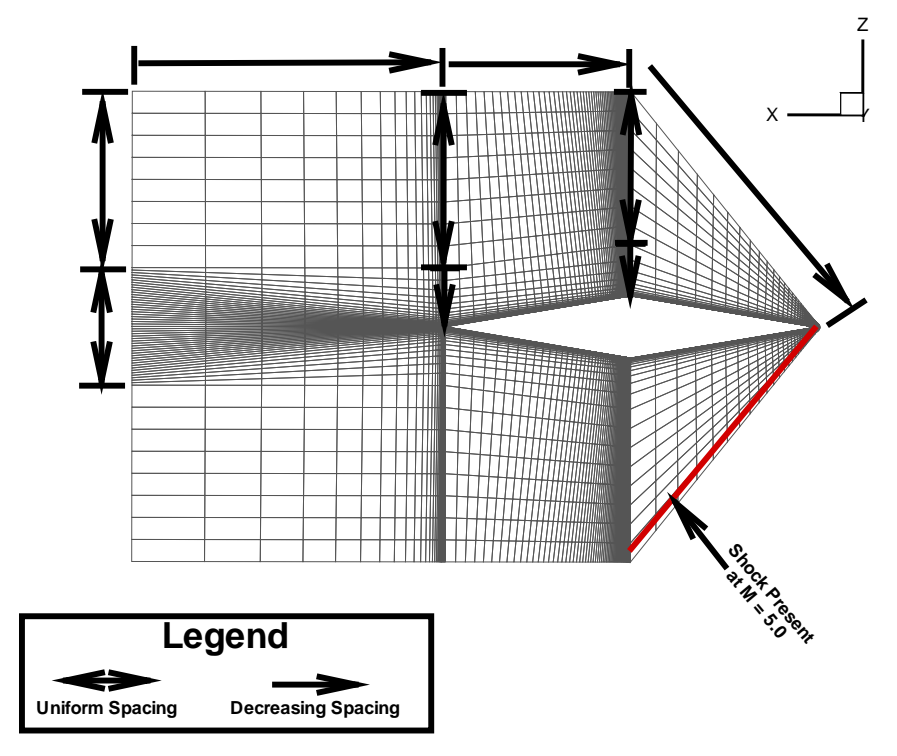

Figure 7: Root plane of MESH4.

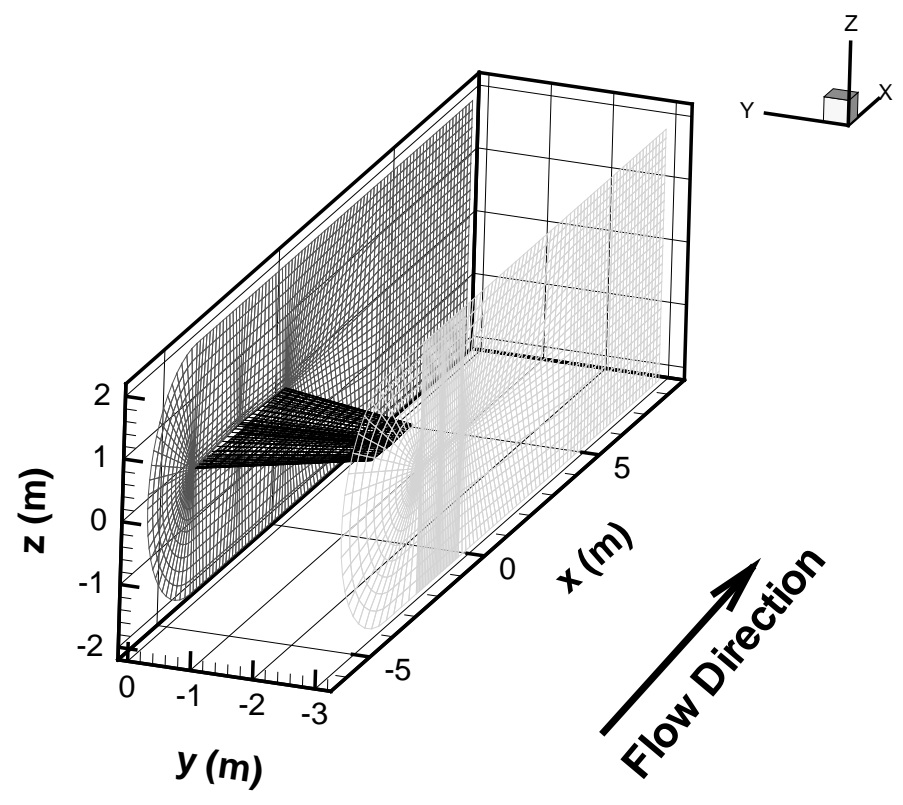

Figure 8: Computational domain of MESH1. 


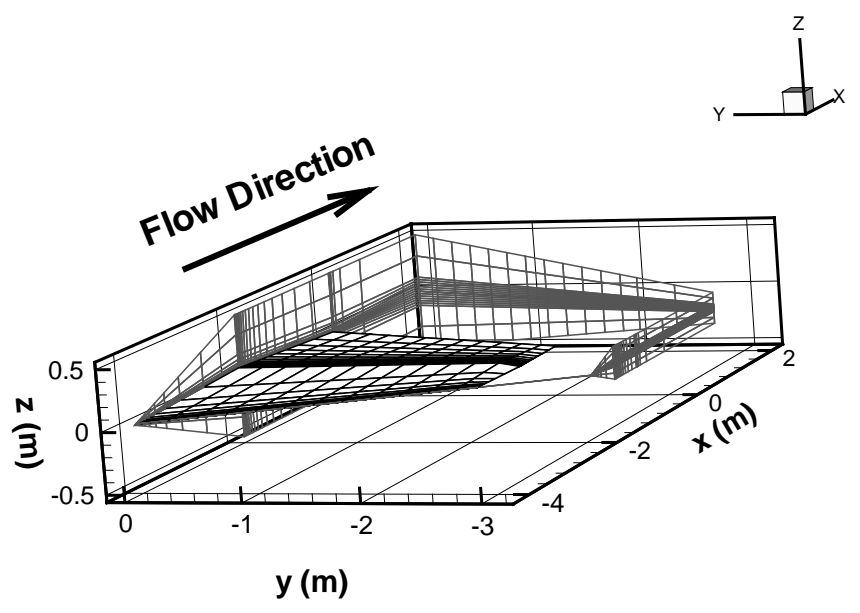

Figure 9: Computational domain of MESH4.

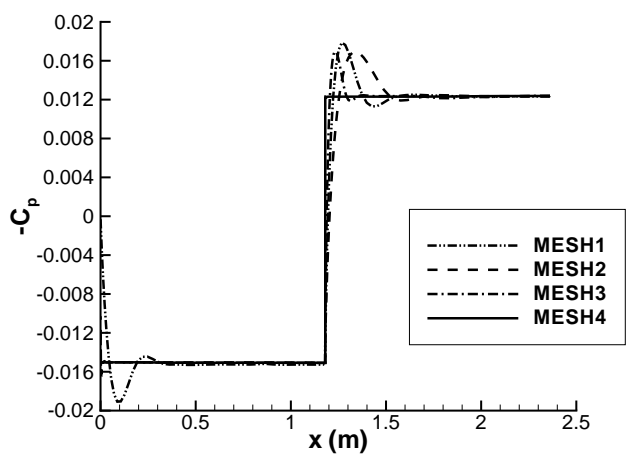

(a) Mach 5, 40,000 ft.

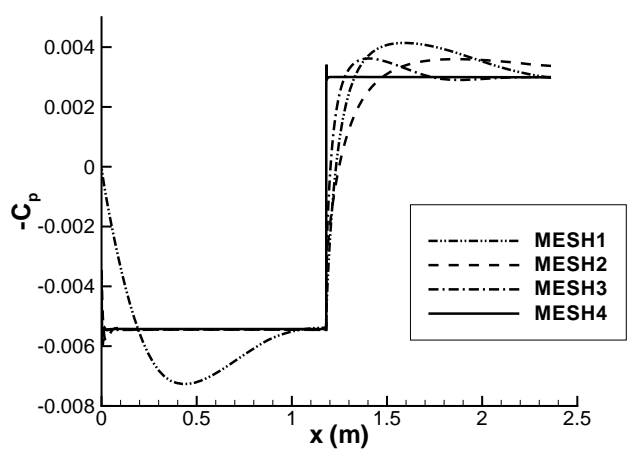

(b) Mach 16, 40,000 ft.

Figure 10: $C_{p}$ from 4 different grids using Euler aerodynamics. Located at the $75 \%$ span of the low aspect ratio wing. 


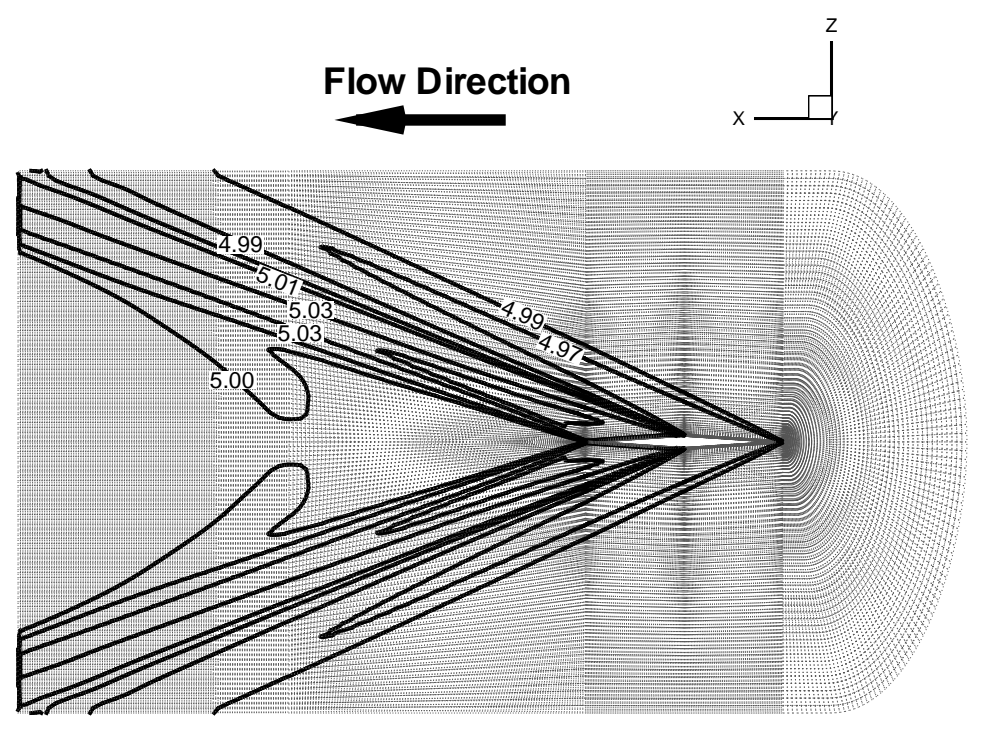

Figure 11: Mach contours of the flow at a section located at $75 \%$ span of a low aspect ratio wing for Mesh1 using Euler aerodynamics. $M=5.0,40,000 \mathrm{ft}$. Note that the $\mathrm{z}$ dimension is scaled.

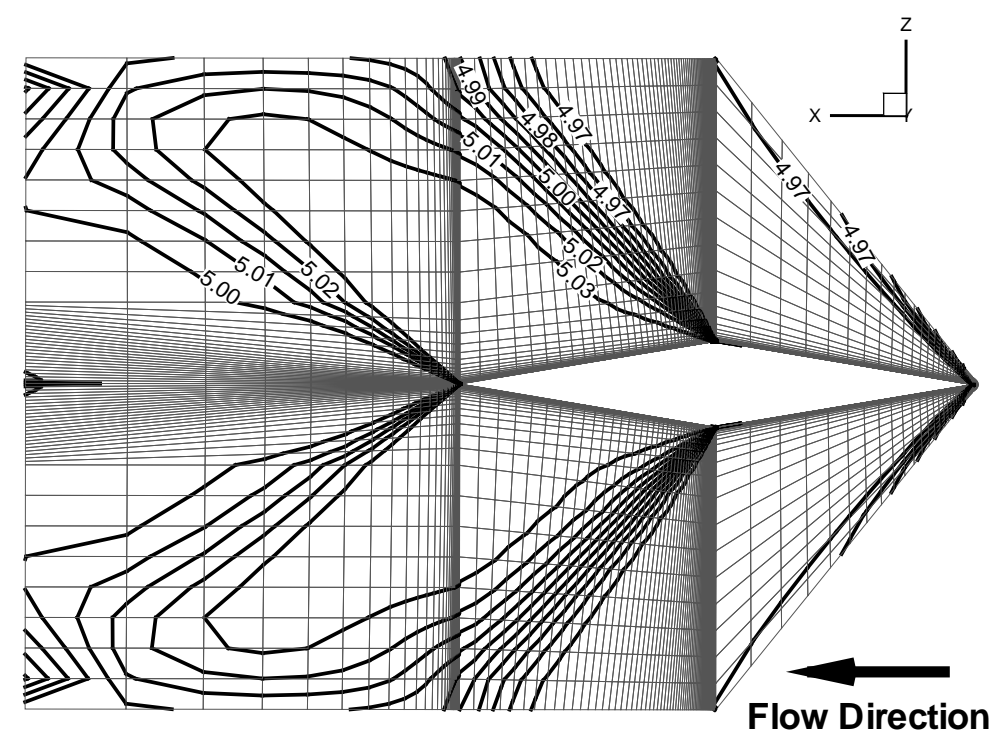

Figure 12: MMach contours of the flow at a section located at $75 \%$ span of a low aspect ratio wing for Mesh4 using Euler aerodynamics. $M=5.0,40,000 \mathrm{ft}$. Note that the z dimension is scaled. 


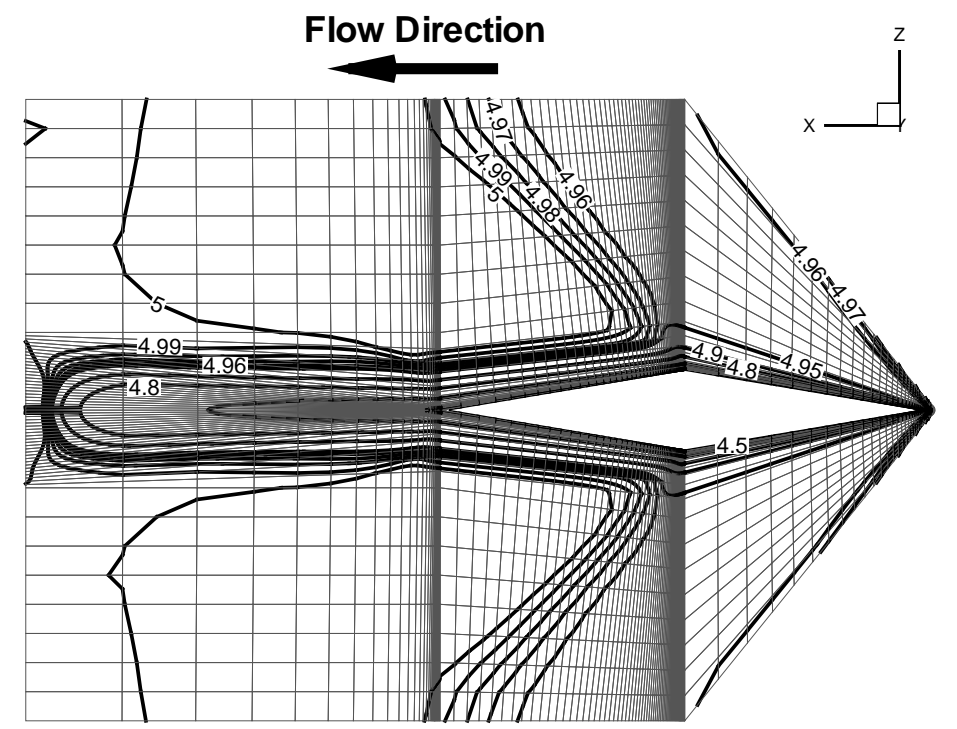

Figure 13: Mach contours of the flow at a section located at $75 \%$ span of a low aspect ratio wing for Mesh4 using Navier-Stokes aerodynamics. $M=5.0,40,000 \mathrm{ft}$. Note that the $\mathrm{z}$ dimension is scaled.

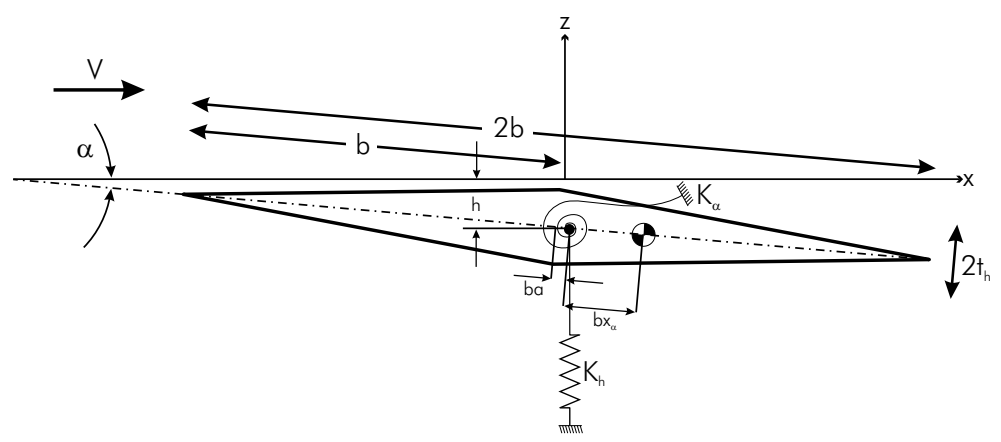

Figure 14: Two degree-of-freedom typical airfoil geometry. 


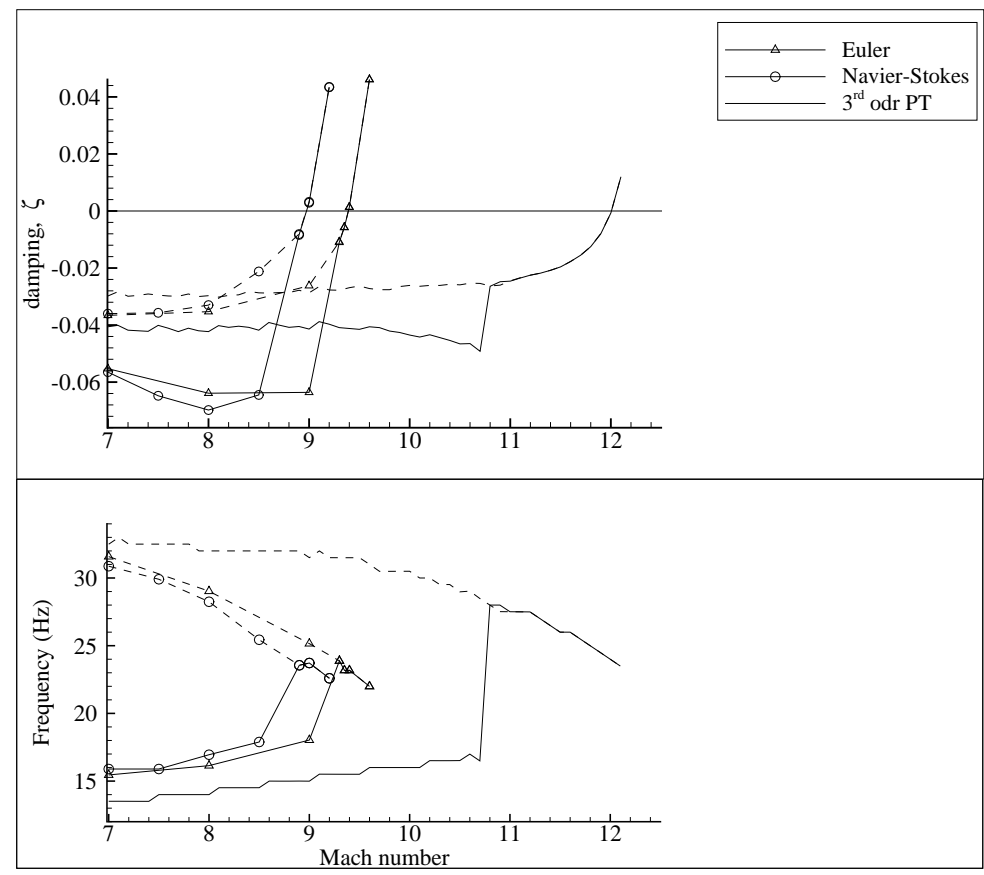

Figure 15: Comparison of aeroelastic results for the double-wedge airfoil, at an altitude of 40,000 feet.
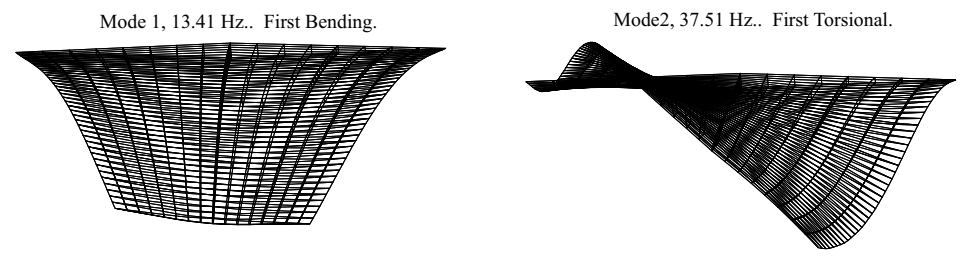

Mode 3, $49.18 \mathrm{~Hz}$. Second Bending.

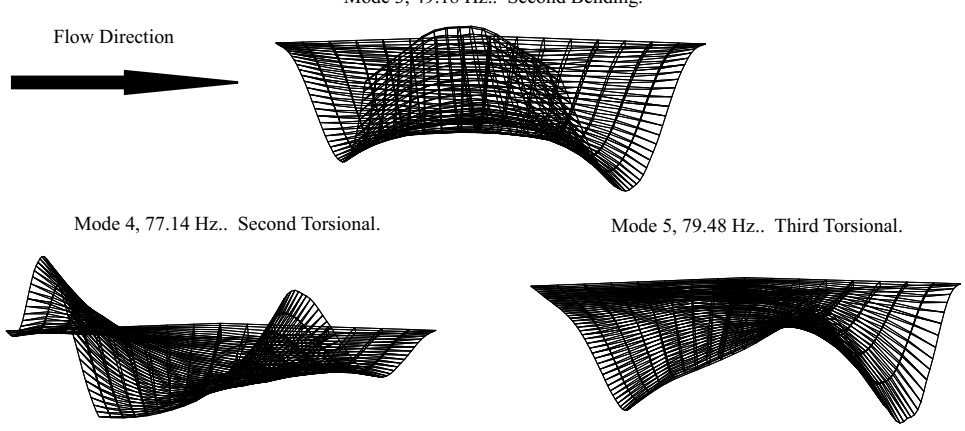

Figure 16: First 5 free vibration modes of the low aspect ratio wing 


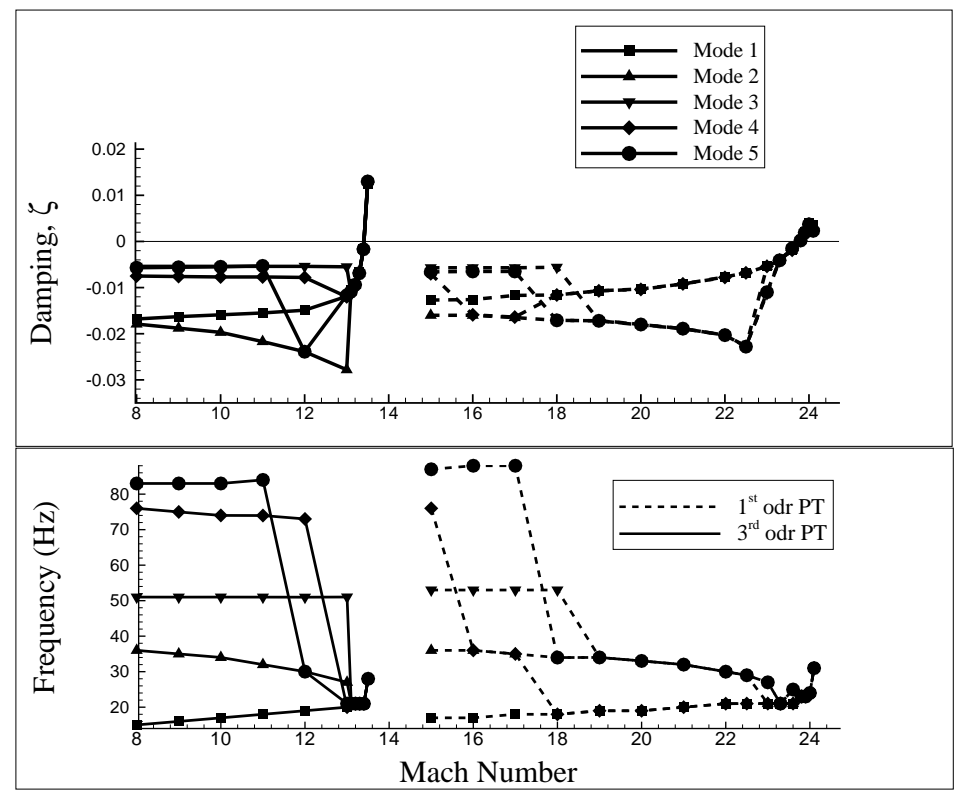

Figure 17: Comparison of aeroelastic behavior of the low aspect ratio wing using 1st and 3rd order piston theory aerodynamics. 40,000ft.
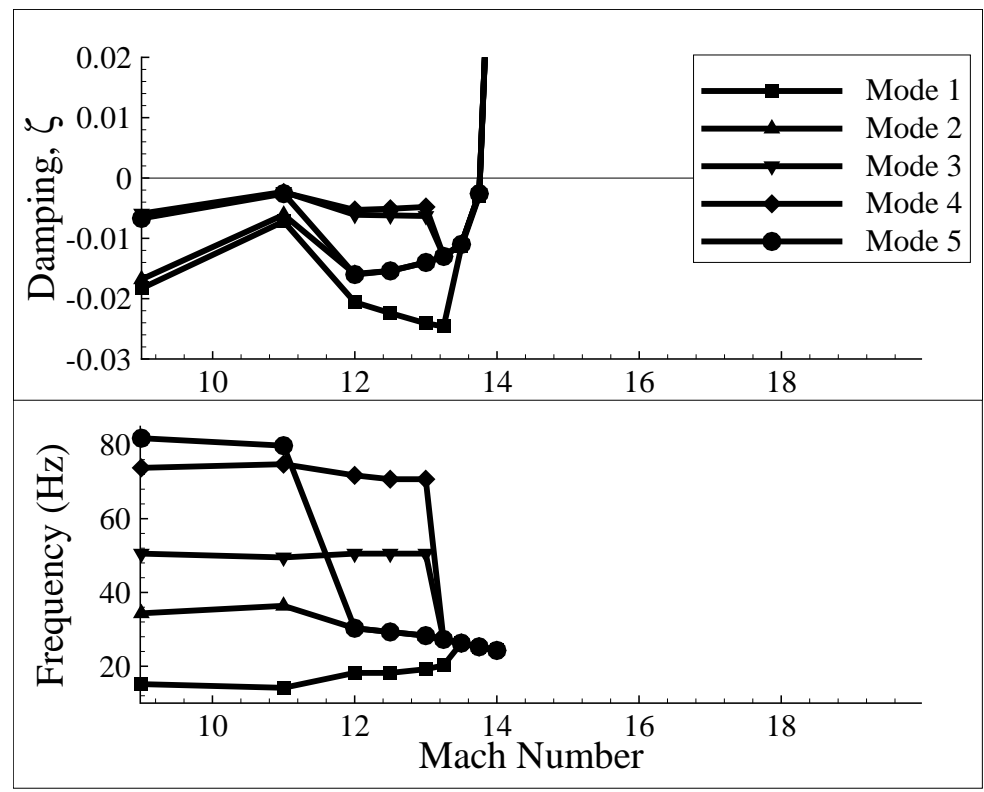

Figure 18: Aeroelastic behavior of the low aspect ratio wing using Euler aerodynamics. 40,000ft. 


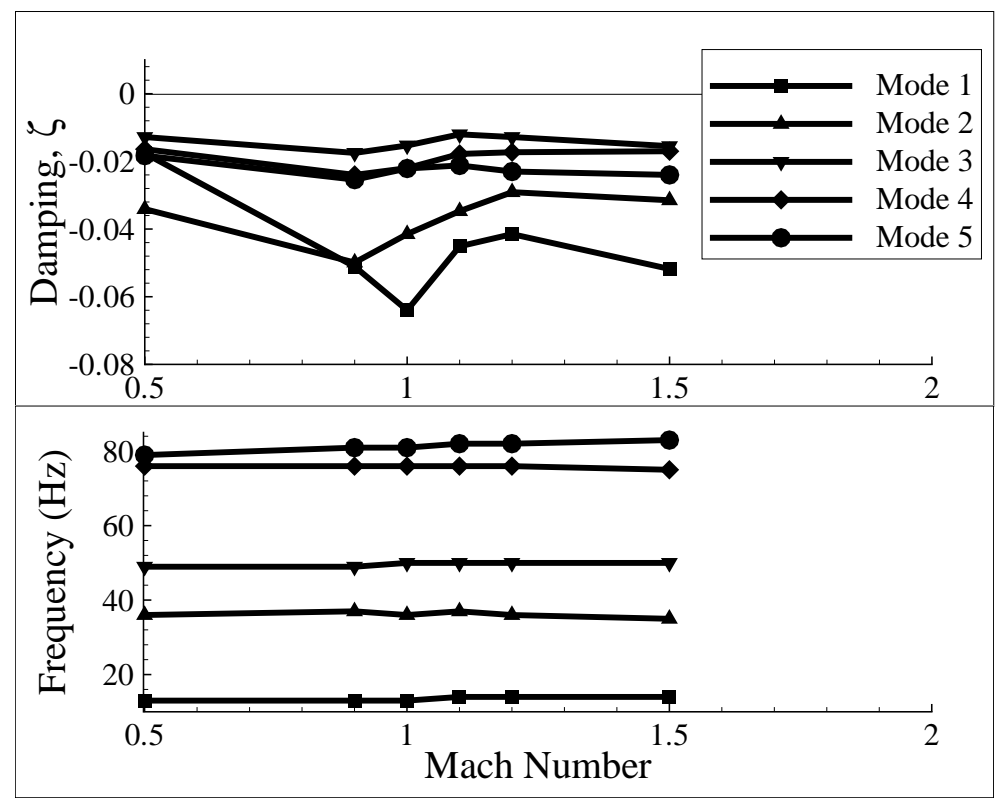

Figure 19: Transonic aeroelastic behavior of the low aspect ratio wing using Euler aerodynamics, sea level.

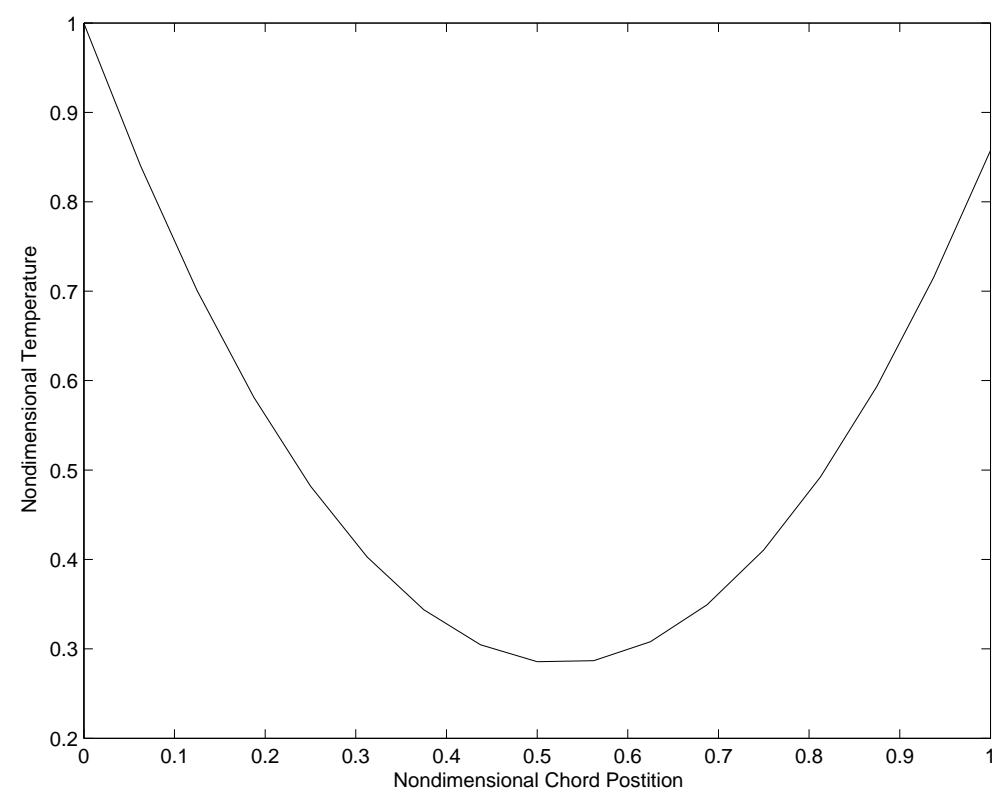

Figure 20: Normalized temperature distribution as a function of chord location. The 0 chord position corresponds to the leading edge. 


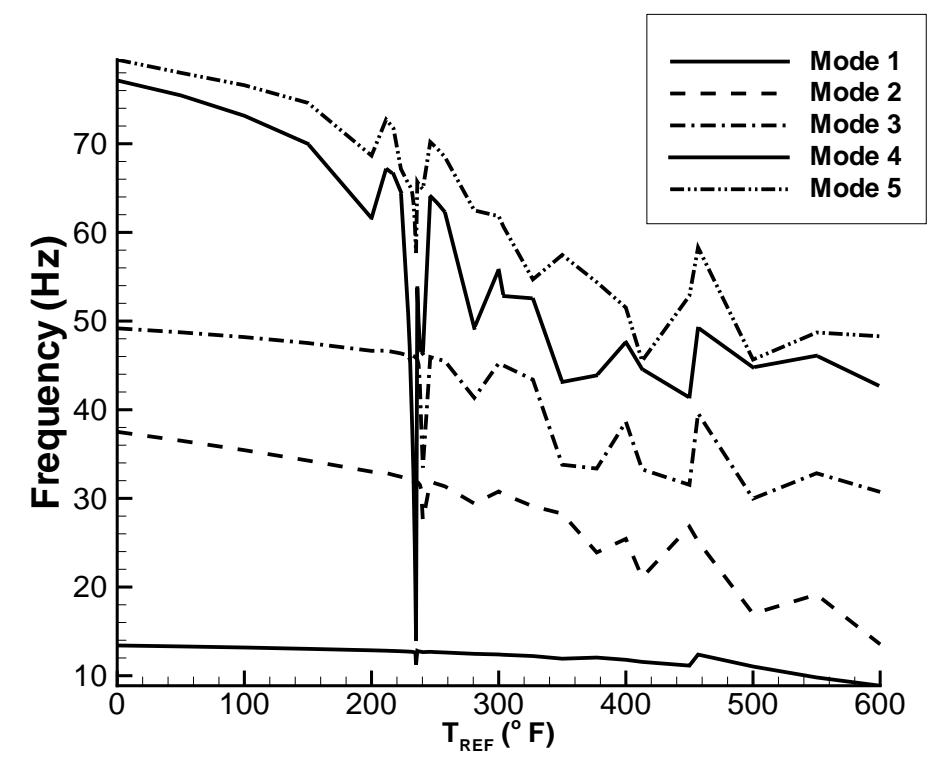

Figure 21: Natural frequencies of a low-aspect ratio wing subject to a non-uniform temperature distribution.
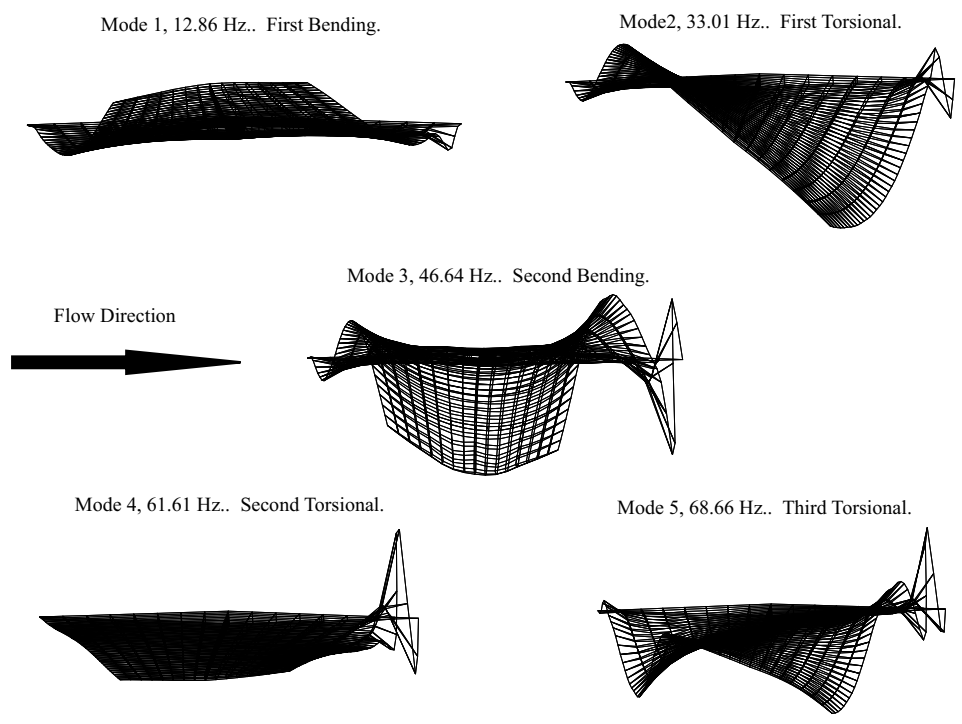

Figure 22: Heated mode shapes of the low aspect ratio wing. $T_{R E F}=200^{\circ}$. 

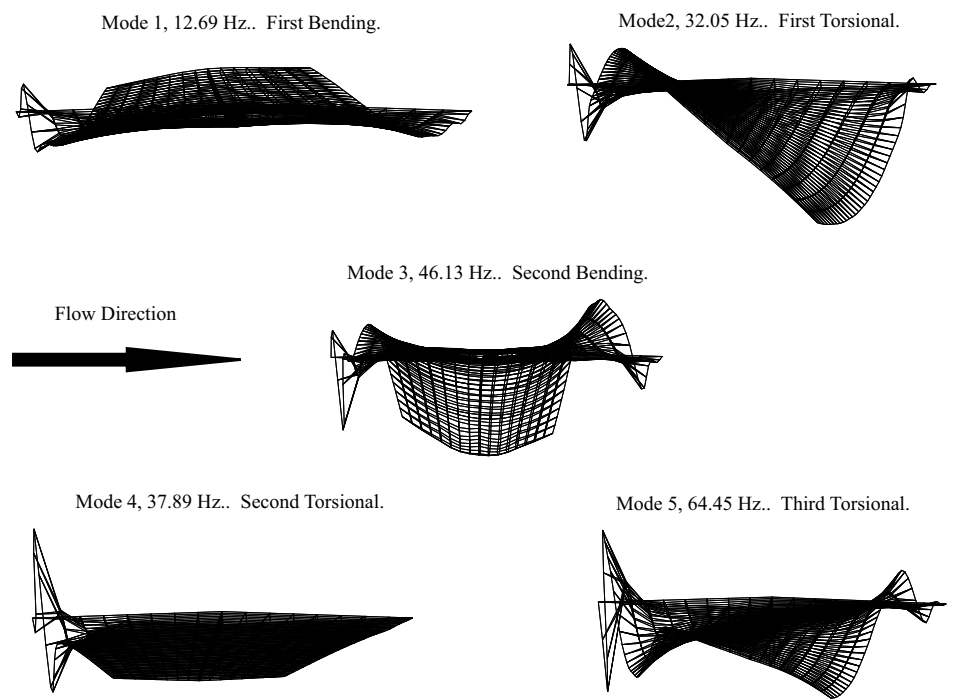

Figure 23: Heated mode shapes of the low aspect ratio wing. $T_{R E F}=232^{\circ}$.
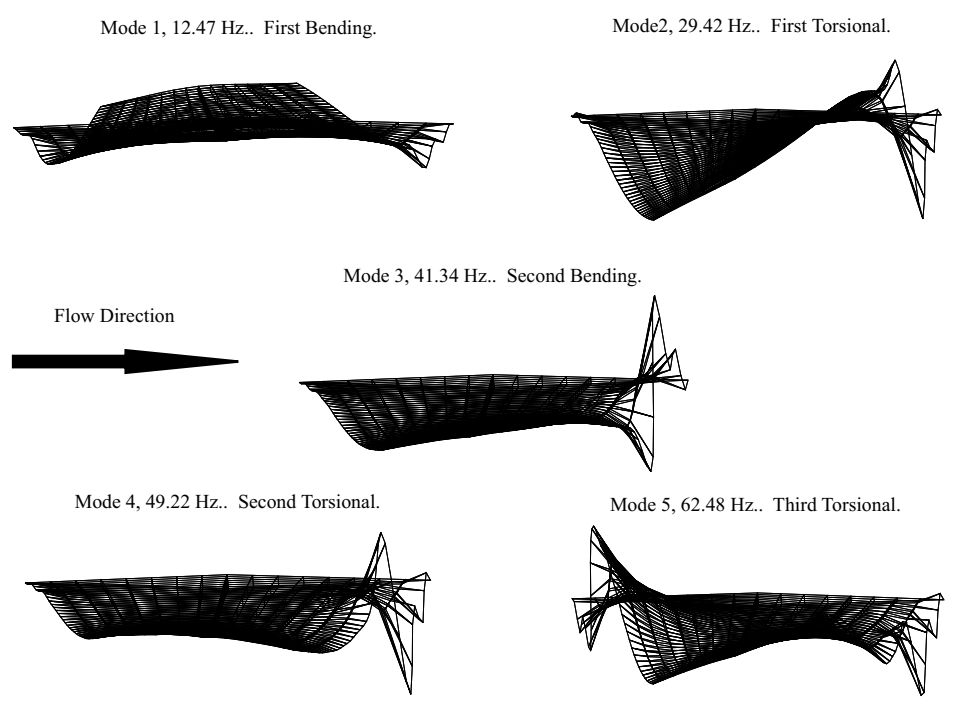

Figure 24: Heated mode shapes of the low aspect ratio wing. $T_{R E F}=281^{\circ}$. 


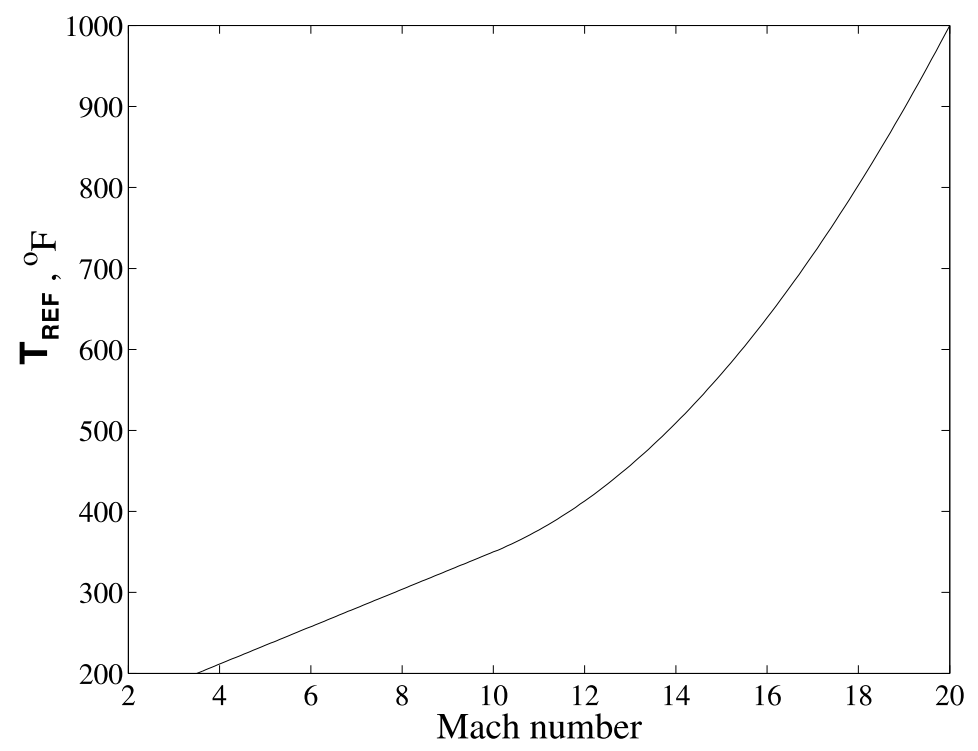

Figure 25: Variation of temperature with Mach number.

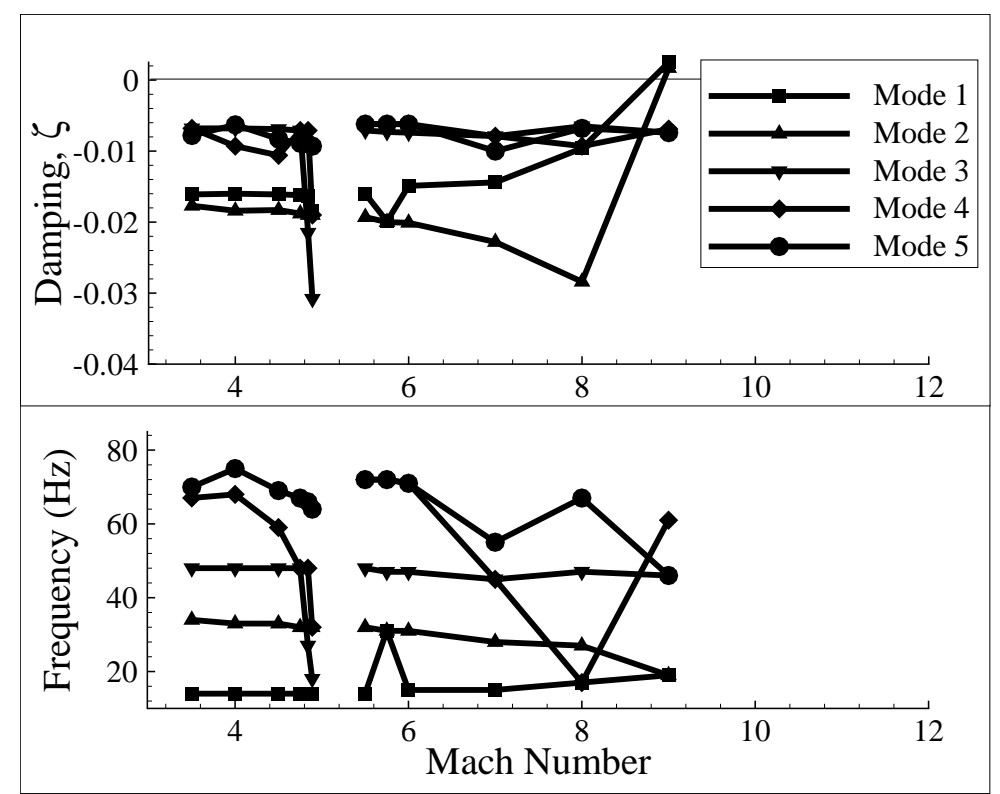

Figure 26: Aeroelastic behavior of the low aspect ratio wing subject to non-uniform heating using 3rd order piston theory aerodynamics. 40,000ft. 


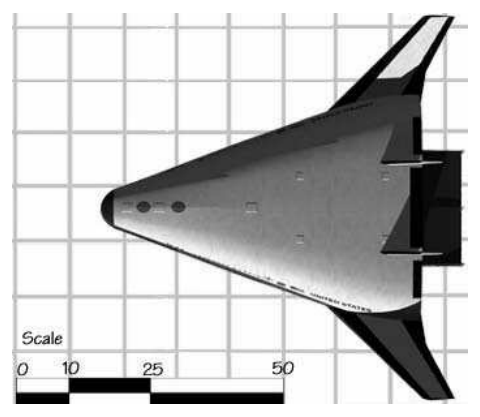

(a) X33, top view.

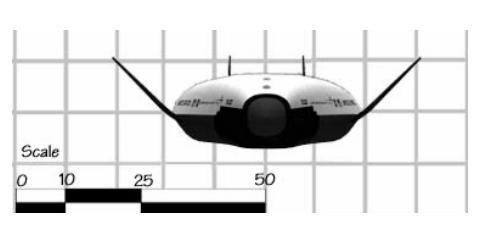

(c) X33, front view.

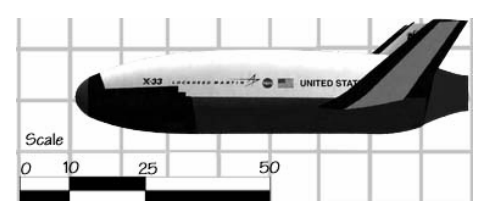

(e) X33, side view

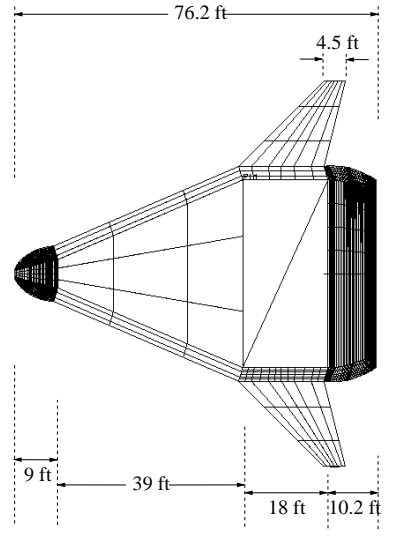

(b) Generic vehicle, top view.

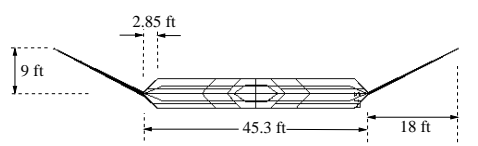

(d) Generic vehicle, front view.

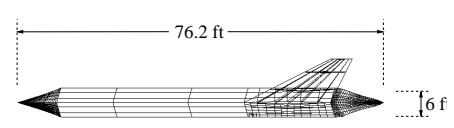

(f) Generic vehicle, side view.

Figure 27: X-33 and generic reusable launch vehicle. 


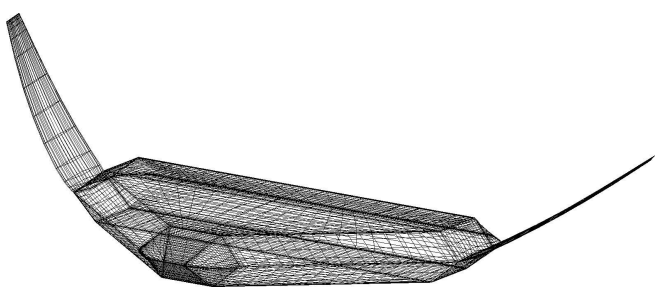

(a) Mode 1, 5.27 Hz. Symmetric fin bending mode.

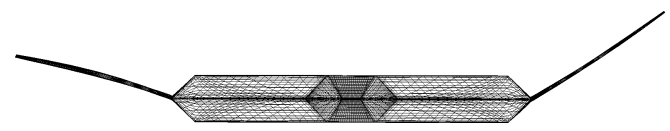

(b) Mode 2, $5.38 \mathrm{~Hz}$. Asymmetric fin bending mode.

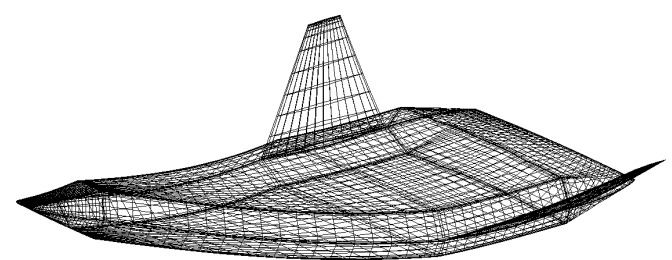

(c) Mode 3, $11.12 \mathrm{~Hz}$. First fuselage bending mode.

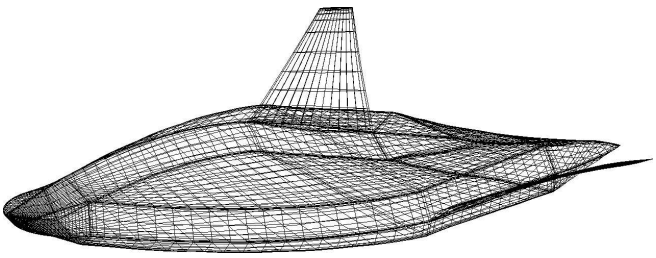

(d) Mode 4, $14.59 \mathrm{~Hz}$. First fuselage torsional mode.

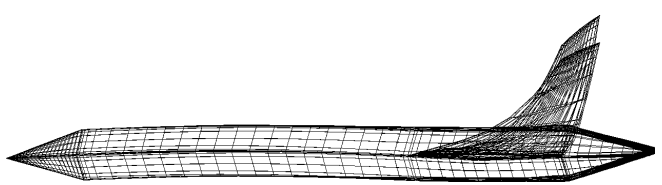

(e) Mode 5, $21.95 \mathrm{~Hz}$. Second fuselage bending mode.

Figure 28: First 5 free vibration modes of the generic reusable launch vehicle. 


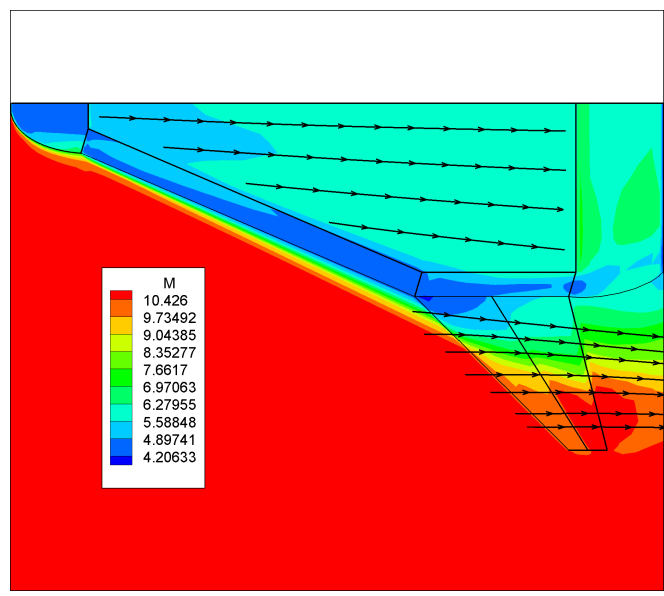

Figure 29: Streamlines and Mach contours on the generic vehicle using Euler aerodynamics, top view, $M=10.5,40,000$ feet.

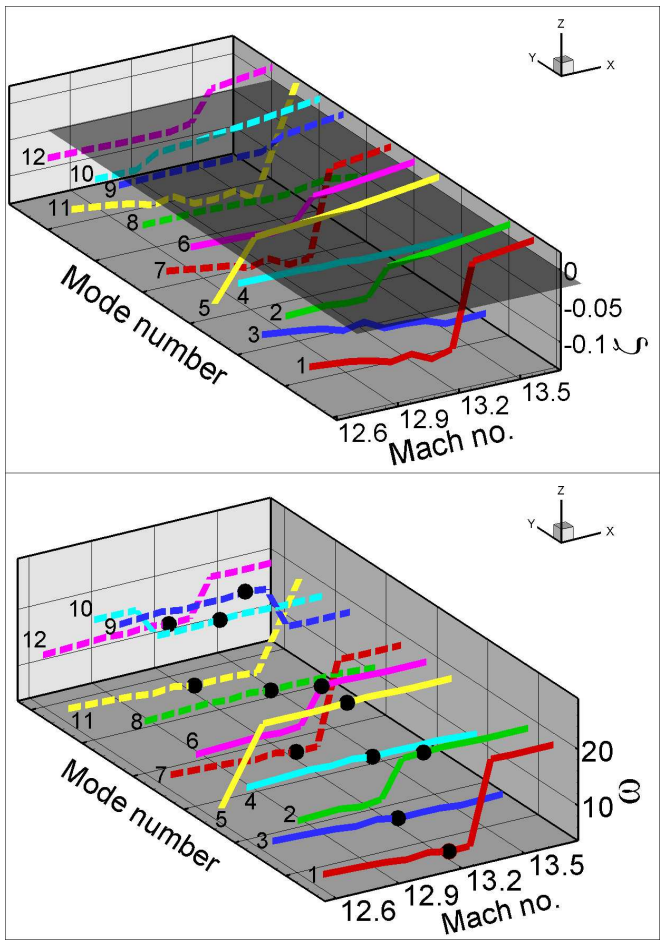

Figure 30: Aeroelastic behavior of the generic vehicle at 40,000 feet, using linear piston theory. The frequencies of the various modes at flutter is shown in the figures by black dots. 


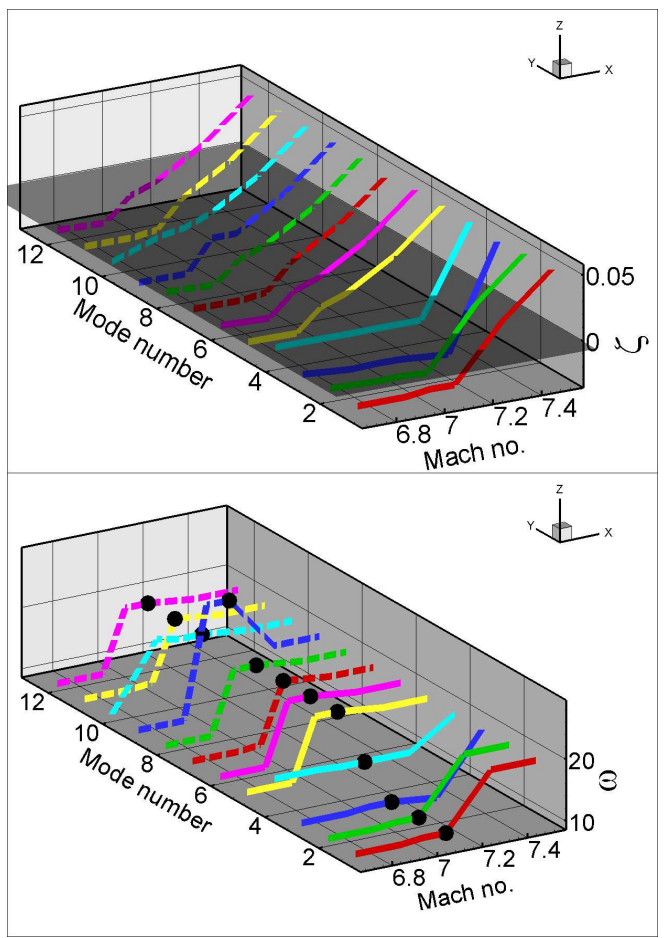

Figure 31: Aeroelastic behavior of the generic vehicle at 40,000 feet, using nonlinear piston theory. The frequencies of the various modes at flutter is shown in the figures by black dots.

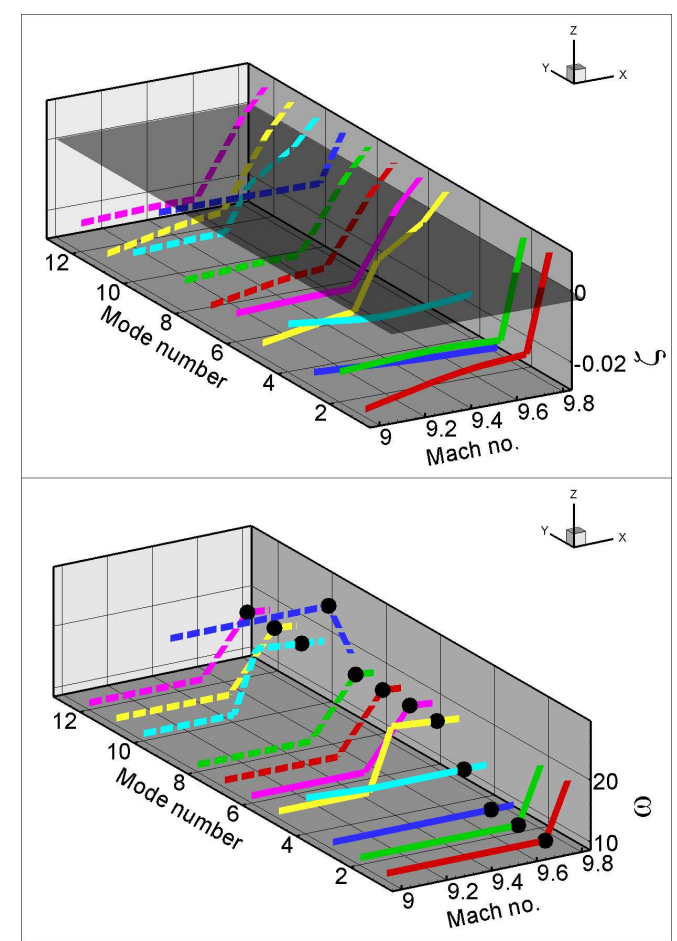

Figure 32: Aeroelastic behavior of the generic vehicle at 50,000 feet, using nonlinear piston theory. The frequencies of the various modes at flutter is shown in the figures by black dots. 


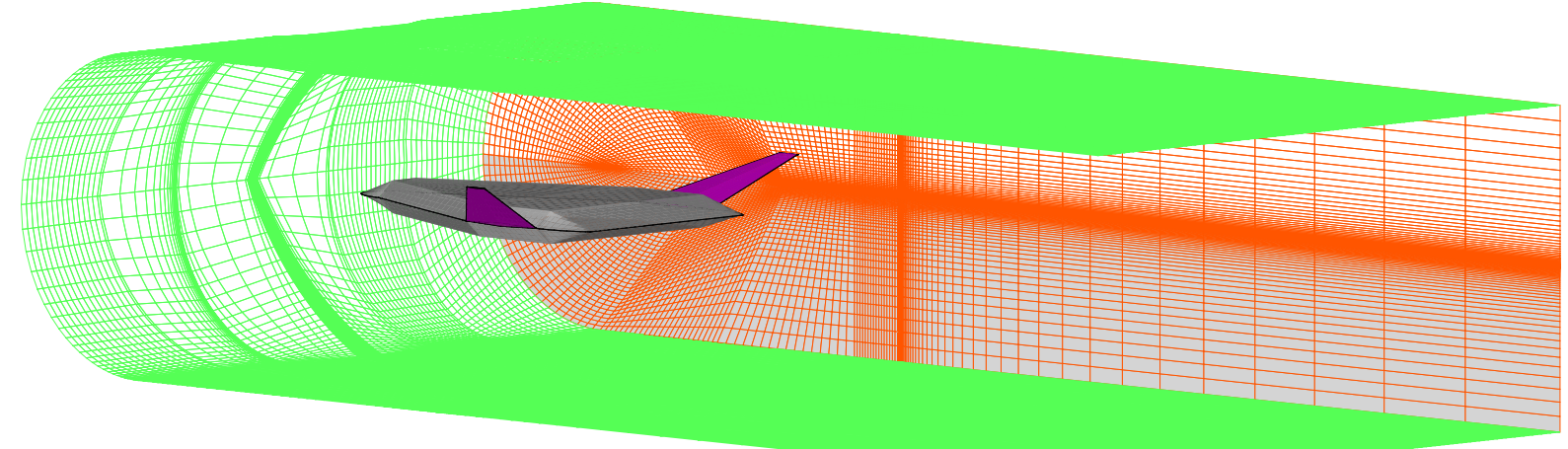

Figure 33: CFD domain for aeroelastic analysis of the generic hypersonic vehicle. 